\title{
ELETROQUÍMICA DAS PARTÍCULAS COLOIDAIS E SUA RELAÇÃO COM A MINERALOGIA DE SOLOS ALTAMENTE INTEMPERIZADOS
}

\author{
Maurício Paulo F. Fontes ${ }^{1,4 *}$; Otávio Antônio de Camargo 2,4 ; Garrison Sposito³ \\ ${ }^{1}$ Depto. de Solos - UFV, CEP: 36571-000 - Viçosa, MG. \\ ${ }_{3}^{2}$ Centro de Solos e Recursos Agroambientais - IAC, C.P. 28 - CEP: 13001-970 - Campinas, SP. \\ ${ }^{3}$ Environmental Geochemistry Group, Division of Ecosystem Sciences, University of California, 94720-3110 - Berkeley, \\ CA, USA. \\ ${ }^{4}$ Bolsista CNPq. \\ *Autor correspondente <mpfontes@mail.ufv.br>
}

\begin{abstract}
RESUMO: O conhecimento das propriedades eletroquímicas das partículas minerais dos solos altamente intemperizados é imprescindível para o avanço dos estudos em diferente áreas da Ciência do Solo, como, Física, Manejo e Conservação, Fertilidade e Poluição do Solo. Nesse contexto, o comportamento das cargas superficiais e seu relacionamento com a mineralogia dos solos de carga variável é de importância fundamental para o entendimento e a melhoria da capacidade preditiva de diversos fenômenos, tais como dispersão e floculação de colóides, troca catiônica, adsorção de ânions, especialmente os fosfatos, adsorção de metais pesados, etc. Assim, essa revisão de literatura faz uma abordagem científica do tema "Eletroquímica das partículas coloidais e sua relação com a mineralogia de solos altamente intemperizados", na qual é contemplado o histórico da evolução do conhecimento nesse campo e os desafios para o aprofundamento das pesquisas futuras na área. As diferentes tendências e posicionamentos existentes na literatura sobre Pontos de Carga Zero (PCZs), Caracterização e Medição de Cargas, Nomenclatura e Simbologia de PCZs e Relacionamento entre Cargas e Minerais de solos altamente intemperizados são também apresentados. Conceituações básicas são revisitadas e conceitos novos ou pouco utilizados na Ciência do Solo são apresentados e discutidos, com o intuito de se melhorar o entendimento e aprimorar a interpretação de tão importante ramo da Química, Mineralogia e Poluição de Solos.
\end{abstract}

Palavras-chave: PCZ, carga superficial, solos tropicais, mineralogia

\section{ELECTROCHEMISTRY OF COLLOIDAL PARTICLES AND ITS RELATIONSHIP WITH THE MINERALOGY OF HIGHLY WEATHERED SOILS}

\begin{abstract}
The knowledge of the electrochemical properties of the mineral particles of highly weathered soils is indispensable for the advance of the studies in different Soil Science areas, like as, Soils Physics, Conservation and Management, Fertility and Pollution. In this context, the surface charge behavior and its relationship with the mineralogy of variable charge soils is of fundamental importance to the understanding and the improvement of the predictive capability of several phenomena, such as, floculation and dispersion of colloids, cations exchange, anion adsorption, specially phosphates, heavy metals adsorption, etc. Therefore, this literature review aims at to make a scientific approach of the topic "Electrochemistry of colloidal particles and its relationship with the mineralogy of highly weathered soils", in which, the historical evolution of the knowledge in this field is covered and the challenges to the development of the research in this area are raised. Different tendencies and views existing in the literature about Zero Points of Charge (ZPC), Charge Characterization and Measurement, ZPCs Terminology and Simbology and Relationship between Charge and Minerals of the highly weathered soils are also presented. Basic concepts are revisited and new or seldom used concepts in Soil Science are presented and discussed with the objective of improving the understanding and refining the interpretation of such important branch of the Soil Chemistry and Mineralogy field.
\end{abstract}

Key words: ZPC, surface charge, tropical soils, mineralogy

\section{INTRODUÇÃO}

O estudo das cargas elétricas das partículas coloidais é de fundamental importância para o entendimento de diversos fenômenos físico-químicos que ocorrem nos solos, já que a maioria das reações eletroquímicas que influenciam sua fertilidade e a nutrição de plantas e que podem interferir em fenômenos relacionados ao seu manejo e conservação ocorre na superfície dessas partículas.

Nas últimas décadas, a investigação de atributos eletroquímicos de solos tropicais tem aumentado muito, principalmente após o trabalho de Raij \& Peech (1972), e tem abrangido pesquisas em diferentes tipos de solos, 
predominando os Oxissolos e Ultissolos (Gallez et al., 1976; Tessens \& Zauyah, 1982; Magalhães \& Page, 1984a; Wada \& Wada, 1985; Cochrane \& Souza, 1985; Gillman \& Sumner, 1987; Charlet \& Sposito, 1987; Sakurai et al., 1990; Perez et al., 1993; Alleoni \& Camargo, 1994a, 1994b; Silva et al.,1996; Dynia \& Camargo, 1998), seguidos dos Inceptissolos (Balasubramanian \& Kanehiro, 1978; Gillman, 1984a), Alfissolos ( Raij \& Peech, 1972; Hendershot, 1978), e Andossolos ( Fey \& Roux, 1976; Okamura \& Wada, 1983). Alguns destes solos foram comparados com os pertencentes a outras ordens, como Molissolos (Parker et al., 1979; Stoop, 1980, Espodossolos (Laverdière \& Weaver, 1977), e Entissolos (Mekaru \& Uehara, 1972).

O ponto de carga zero (PCZ) é uma das mais importantes propriedades do solo para a descrição de fenômenos decorrentes da dupla camada elétrica de interfaces reversíveis (Raij, 1973; Sakurai et al., 1989; Zhang \& Zhao, 1997). Além disso, é usado para a determinação de vários atributos pedológicos, tais como desenvolvimento pedogenético (Hendershot \& Lavkulich, 1978), topossequência (Lepsch \& Buol, 1974) ou cronossequência (Hendershot et al., 1979; Parker et al., 1979).

A reconhecida importância do PCZ fez com que inúmeros trabalhos fossem realizados envolvendo desde métodos de determinação até práticas de manejo (Rojas \& Adams, 1980; Naidu et al., 1990), para procurar modificar seu valor para níveis mais adequados para absorção de nutrientes pelas plantas. Porém, existe muita ambigüidade em torno do conceito de PCZ quando se compara sua aplicação no sistema solo com relação a sua aplicação em sistemas puros como dos óxidos.

Solos altamente intemperizados, como Latossolos e Argissolos, são predominantes no território brasileiro e de grande relevância na América Latina. Eles ocupam extensas áreas cultivadas e são ainda importantes como reservas naturais, com um papel proeminente na resolução dos problemas relacionados à produção de alimentos e à proteção ao meio ambiente.

Por serem solos com grau de intemperismo mais elevado, possuem mineralogia da fração argila dominada por minerais silicatados do tipo 1:1 e óxidos ${ }^{1}$ de Fe, Al além de, ocasionalmente, de Mn. Aparentemente, possuem mineralogia simples, mas uma observação mais atenta na literatura demonstra que existe imensa variabilidade no comportamento desses poucos minerais. De modo geral, esses solos apresentam pequenas quantidades de minerais como micas e vermiculita com hidroxi-entrecamadas (VHE), o que pode, em certos casos, ser importante em algumas propriedades físicoquímicas.

Caulinita é o principal e virtualmente o único mineral silicatado em quantidade expressiva; goethita e hematita são os principais óxidos de $\mathrm{Fe}$, e gibbsita é praticamente o único óxido de Al presente nesses solos. Contudo, todos eles mostram grande diversidade de características como tamanho de partículas, faces expostas, graus de substituição isomórfica, grau de envelhecimento, etc., o que os induzem a comportamentos bem diferenciados quanto a importantes reações do solo. A diversidade das características é atribuída, principalmente, aos diferentes ambientes de formação a que esses minerais estão sujeitos.

Pela sua formação e por influência de sua mineralogia, os solos altamente intemperizados e com carga variável apresentam propriedades agronomicamente desejáveis como boa profundidade, estrutura estável, boa porosidade e alta permeabilidade. Por outro lado, eles também apresentam propriedades de alguma forma indesejáveis como alta acidez, baixa reserva de nutrientes, baixa capacidade de troca catiônica, alta capacidade de adsorção aniônica (especialmente fosfato) e PCZ alto.

A maioria dessas propriedades está ligada direta ou indiretamente ao desenvolvimento e ao balanço de cargas elétricas na superfície das partículas que compõem seu sistema coloidal. Assim sendo, a caracterização da carga elétrica superficial de partículas dos solos predominantes em regiões tropicais e subtropicais torna-se parte essencial da maioria dos estudos sobre eles conduzidos. Apesar da reconhecida importância da matéria orgânica nos fenômenos de desenvolvimento e balanço de cargas, principalmente nos horizontes superiores do solo, a ênfase será dada aos materiais inorgânicos.

Esta revisão tem como objetivos principais: a) destacar e conceituar alguns aspectos fundamentais das reações eletroquímicas, o seu envolvimento com o ponto de carga zero e a sua relação com a mineralogia de solos com cargas variáveis; e b) indicar caminhos a serem pesquisados em solos altamente intemperizados para o desenvolvimento e elucidação de pontos importantes sobre o tema.

\section{DESENVOLVIMENTO DE CARGAS NOS CONSTI- TUINTES DOS SOLOS}

As superfícies dos materiais coloidais do solo são carregadas eletricamente, o que significa que essas superfícies têm um excesso ou um déficit de elétrons (Uehara \& Gillman, 1981) que, em conjunto com os íons presentes na solução do solo, constituem uma dupla camada de cargas (van Olphen, 1977). Com a distribuição de cargas, um potencial elétrico máximo se desenvolve na superfície da partícula e decresce com a distância na solução. Se a dupla camada de cargas for resultado de imperfeições internas e substituições isomórficas estruturais, a densidade de cargas é constante, ao passo que o potencial elétrico de superfície

${ }^{1}$ Para brevidade e simplicidade no texto, o termo geral óxidos se refere a óxidos, hidróxidos e oxihidróxidos 
é variável. Se a dupla camada for criada pela adsorção de íons determinantes de potencial (IDP), a densidade de cargas é variável enquanto que o potencial elétrico de superfície é constante e é determinado somente pela concentração ou atividade desses íons em solução.

\section{Carga Permanente}

As cargas permanentes são produto das substituições iônicas isomórficas nas estruturas minerais e sempre se manifestam em qualquer $\mathrm{pH}$ dos solos. Esta carga é inerente ao mineral e pode também ser chamada de carga estrutural. As substituições iônicas isomórficas, simplificadamente chamadas de substituições isomórficas, ocorrem nos minerais primários, na sua diferenciação magmática, e nos secundários na sua formação no solo ou pela herança de minerais primários. Mas elas produzem carga significativa apenas nos minerais argilosos silicatados do tipo 2:1 e em alguns poucos minerais primários, tipo mica, quando esses atingem tamanho pequeno o suficiente para compor a fração argila dos solos. Smith \& Emerson (1976) afirmam que a caulinita (argila do tipo 1:1) também possui carga negativa permanente, em adição à carga variável, mas que ela é pequena e de pouca expressão. Teoricamente, a carga permanente pode ser negativa ou positiva, contudo, em função de tamanhos iônicos, a substituição se faz, normalmente, por um elemento de menor valência substituindo o de maior valência $\left(\mathrm{Al}^{3+} \rightarrow \mathrm{Si}^{4+}, \mathrm{Mg}^{2+} \rightarrow\right.$ $\left.A l^{3+}\right)$, o que leva a déficit de carga positiva na estrutura cristalina e a manifestação de carga negativa na superfície do colóide (Gast, 1977). Tessens \& Zauyah (1982) postulam a existência de carga permanente positiva em solos altamente intemperizados e relacionam essas cargas à substituição de $\mathrm{Fe}^{3+}$ por $\mathrm{Ti}^{4+}$ na estrutura dos óxidos de Fe.

\section{Carga Variável}

Cargas variáveis são aquelas originárias da adsorção de íons na superfície dos colóides do solo, sendo a carga líquida determinada pelo íon que é adsorvido em excesso. Íons capazes de interferir na carga ao serem adsorvidos são chamados íons determinantes de potencial. Como os principais íons determinantes de potencial na solução do solo são $\mathrm{H}^{+} \mathrm{e}$ $\mathrm{OH}^{\prime}$, esses colóides são também chamados de colóides de carga dependente do $\mathrm{pH}$. Se se levar em consideração que outros íons podem atuar como determinantes de potencial o termo mais genérico colóides de carga variável deve ser preferido (Uehara \& Gillman, 1981). Caulinita, goethita, hematita e gibbsita são os principais minerais do solo que apresentam essa característica.

Na matéria orgânica, a carga variável é negativa e tem sua origem na dissociação de hidroxilas de grupamentos carboxílicos, fenólicos, enólicos etc. Ela desenvolve-se a valores de $\mathrm{pH}$ bem mais baixos do que nos óxidos, sendo menos provável a ocorrência de cargas positivas nestes materiais, nas condições de $\mathrm{pH}$ do solo.
Uma característica essencial à formação e desenvolvimento de cargas nos colóides de carga variável é a possibilidade da hidroxilação da sua superfície. Na presença de água, os íons $\mathrm{Si}, \mathrm{Al}$ ou Fe, por exemplo, localizados na superfície de minerais como caulinita, hematita, goethita e gibbsita, completam sua camada de coordenação com íons hidroxila de modo que toda superfície se torna hidroxilada (Stumm, 1992). A figura 1 mostra a representação do fenômeno.

Nessa representação se introduz o conceito de que os grupamentos hidroxila nesses minerais podem estar ligados a um, dois, ou até três metais na estrutura do mineral, de acordo com a proposição de Russel et al. (1974) e Parfitt et al. (1975). Assim, podem ser chamados de hidroxila de coordenação simples, dupla e tripla, respectivamente.

$\mathrm{Na}$ camada hidroxilada, cargas positivas ou negativas podem ser criadas (Parks \& de Bruyn, 1962; Herbillon, 1988) por protonação ou desprotonação do grupamento hidroxila de acordo com esquema mostrado na figura 2, para óxidos em configuração octaédrica e metal trivalente.

A carga e o potencial da superfície variam com a concentração de $\mathrm{H}^{+}$e $\mathrm{OH}^{-}$, íons determinantes de potencial (IDP). Para uma mesma concentração de $\mathrm{H}^{+}$ ou $\mathrm{OH}^{-}$, o potencial se mantêm constante mas a carga de superfície varia com a concentração e valência dos eletrólitos (força iônica) da solução.

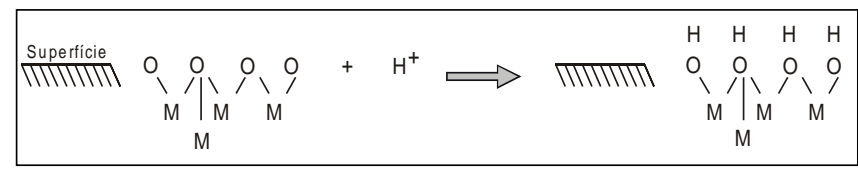

Figura 1 - Hidroxilação de superfícies de minerais que apresentam cargas dependentes de $\mathrm{pH}$. M é o metal estrutural do mineral podendo ser $\mathrm{Si}, \mathrm{Fe}, \mathrm{Al}, \mathrm{Mn}$, etc.

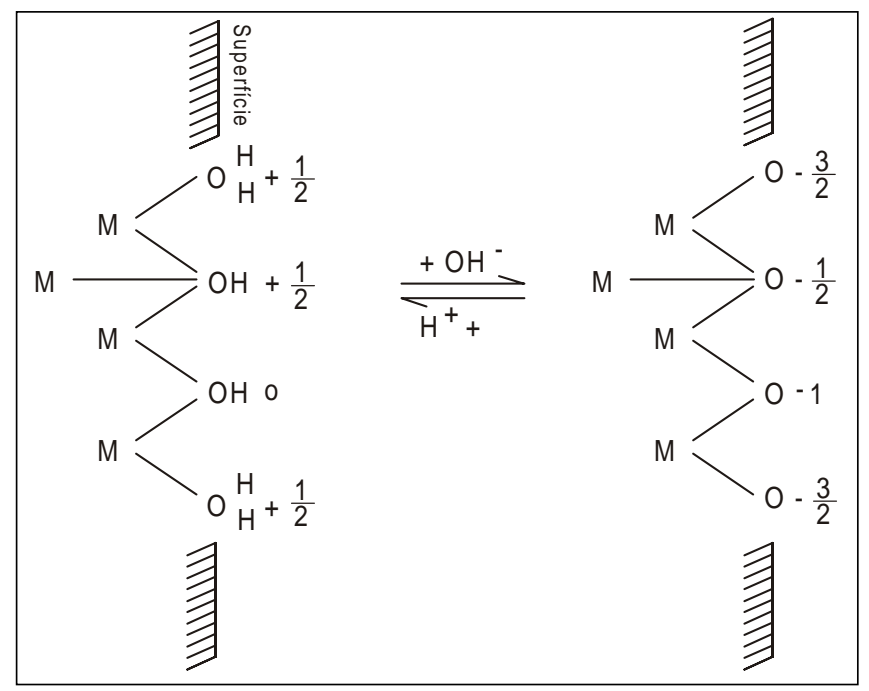

Figura 2 - Distribuição das cargas de grupamentos superficiais típicos de óxidos em configuração octaédrica e metal trivalente. 
A Figura 2 mostra os casos extremos de protonação com formação do máximo de cargas positivas, e desprotonação com formação do máximo de carga negativa. Entre os extremos de carga positiva e negativa há um ponto em que a carga é zero ou pela ausência de cargas ou pela presença de quantidades iguais de carga positiva e negativa. Esse ponto recebe a denominação genérica de ponto de carga zero (PCZ).

PCZs: Definições e Simbologia da Literatura

A definição mais utilizada na literatura é a de Parks \& Bruyn (1962): Ponto de carga zero (PCZ) = valor de $\mathrm{pH}$ para o qual a carga superficial de um sistema reversível de dupla camada é zero, sendo determinado por um valor particular de atividade dos íons determinantes de potencial na fase sólida. Esta definição foi usada por Raij \& Peech (1972), Espinoza et al. (1975) e Arnold (1977), entre outros, sendo também complementada por Laverdière \& Weaver (1977), que acrescentaram que neste ponto o potencial elétrico superficial é também nulo. Entretanto, eles representaram este atributo como $\mathrm{pH}_{\mathrm{pcz}}$. Hendershot \& Lavkulich (1978) complementaram que a carga líquida total da fase sólida no PCZ é nula, seja ela oriunda de cargas dependentes de $\mathrm{pH}$, associadas com superfícies de óxidos hidratados, seja da matéria orgânica. De acordo com Sposito (1989), a condição do PCZ é obtida experimentalmente no valor de $\mathrm{pH}$ no qual as partículas do solo não se movem num campo elétrico aplicado ou quando ocorre assentamento ou floculação delas. Este ponto aparece quando o valor da densidade de cargas dissociadas é zero $\left(\sigma_{D}=0\right)$. Quando medido eletrocineticamente, ele é igual ao ponto isoelétrico. É bom lembrar que o PCZ geralmente representa o $\mathrm{pH}$ de máxima aglomeração de partículas e o menor potencial de solubilização do mineral (Parks \& de Bruyn, 1962).

Diferentes minerais do solo apresentam PCZ a diferentes concentrações de $\mathrm{H}^{+}$, ou seja, a diferentes valores de $\mathrm{pH}$ que variam de $\mathrm{pH} 2$ a 4 para alguns óxidos de Si e Mn até pH 8 a 10 para alguns óxidos de Fe e Al. Por definição os minerais apresentam PCZs baixos ou altos conforme possuam pontos de carga zero a baixo $\mathrm{pH}$ (alta atividade de $\mathrm{H}^{+}$) ou a alto $\mathrm{pH}$ (baixa atividade de $\mathrm{H}^{+}$), respectivamente.

A variação dos valores de $\mathrm{PCZ}$ dos vários minerais do solo parece depender essencialmente da natureza acídica dos diversos grupamentos $\mathrm{OH}$ que aparecem em suas superfícies. Greenland \& Mott (1978) usam o conceito de acidez e alcalinidade para representar a extensão da associação ou dissociação de prótons na superfície dos minerais da seguinte forma:

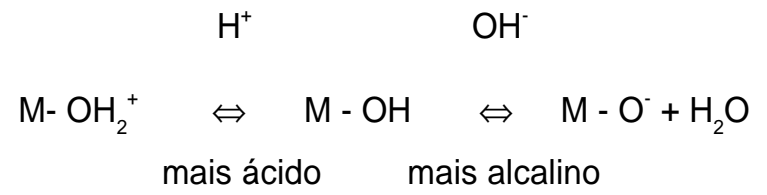

onde $\mathrm{M}$ representa o metal coordenado ou o íon silício na superfície de argila. Mais recentemente, Barrow (1987), Stumm (1992) e McBride (1994), seguindo uma tendência geral na literatura, utilizaram os conceitos do equilíbrio ácido-base e das constantes de dissociação ácida $(\mathrm{Ka})$ para descrever as reações de protonação e desprotonação das superfícies minerais oxídicas e seus grupamentos funcionais da seguinte forma:

$$
\begin{aligned}
& \mathrm{M}-\mathrm{OH}_{2} \Leftrightarrow \mathrm{M}-\mathrm{OH}+\mathrm{H}^{+} \\
& \mathrm{K}_{\mathrm{a} 1}=\frac{\{\mathrm{M}-\mathrm{OH}\}\left[\mathrm{H}^{+}\right]}{\{\mathrm{M}-\mathrm{OH}\}} \\
& \mathrm{M}-\mathrm{OH} \Leftrightarrow \mathrm{M}-\mathrm{O}+\mathrm{H}^{+} \\
& \mathrm{K}_{\mathrm{a} 2}=\frac{\{\mathrm{M}-\mathrm{O}\}\left[\mathrm{H}^{+}\right]}{\{\mathrm{M}-\mathrm{OH}\}}
\end{aligned}
$$

na qual \{ \} é concentração da espécie de superfície em mol kg-1 de adsorvente sólido, [ ] é concentração de solutos em mol $\mathrm{L}^{-1}$, e $\mathrm{M}$ é um metal ou íon silício na estrutura do mineral em coordenação com oxigênios ou hidroxilas.

Devido à natureza ácida dos grupamentos $\mathrm{OH}$, tem-se recorrido às constantes de dissociação ácida para explicar a variação do PCZ para os minerais, e diversos modelos explicativos têm sido formulados. É bom destacar que o conceito de PCZ para solos com predominância de argila de carga permanente tem significado muito restrito.

\section{Ponto Isoelétrico}

O ponto isoelétrico (PIE) é um atributo fundamental em Química Coloidal, sendo que na Química do Solo, às vezes, ele se confunde com o PCZ (Camargo \& Alleoni, 1995), embora diversos autores tenham sugerido várias diferenças entre eles (White \& Zelazny, 1986).

Para Parks \& de Bruyn (1962), PIE é o valor de $\mathrm{pH}$ no qual o somatório dos produtos das valências dos cátions por suas respectivas atividades na solução é igual ao somatório dos produtos das valências dos ânions pelas respectivas atividades, sendo o ponto que corresponde à condição de solubilidade mínima de um sólido em equilíbrio com a solução.

O termo PIE foi definido por Uehara \& Gillman (1980) como o pH no qual a carga líquida no plano que separa a dupla camada difusa e a camada de Stern é zero ou como o pH no qual o potencial zeta é igual a zero (Singh \& Uehara, 1998). Para um eletrólito indiferente, na ausência de adsorção específica na camada de Stern, o PIE é o mesmo que o PCZ para um sistema de cargas variáveis puro.

El-Swaify \& Sayegh (1975) definiram o PIE como o valor de $\mathrm{pH}$ no qual as adsorções de $\mathrm{NH}_{4}^{+}$e $\mathrm{Cl}^{-}$(íons utilizados em experimento com um Oxissolo e um Inceptissolo) foram iguais. 
Segundo Hendershot \& Lavkulich (1978), o PIE do sólido, representado por $\mathrm{PIE}(\mathrm{S})$, é o $\mathrm{pH}$ no qual a carga líquida nas superfícies com cargas dependentes de pH é zero. Bell \& Gillman (1978) e Pyman et al. (1979) chamaram de PIES o valor de $\mathrm{pH}$ em que ocorre adsorção igual de $\mathrm{H}^{+}$e $\mathrm{OH}^{-}$. Já para Fernandez Caldas et al. (1980), o PIES corresponde ao pH no qual a soma algébrica das cargas dos íons determinadores de potencial é igual a zero.

\section{Ponto Zero de Titulação}

Ponto zero de titulação (PZT) é o pH ou a faixa de valores de $\mathrm{pH}$ resultantes da reação de superfícies sólidas com variadas concentrações de um eletrólito indiferente, sem que sejam adicionados ácido ou base (Raij \& Peech, 1972; Laverdière \& Weaver, 1977; Parker et al., 1979; Chaves \& Trajano, 1992). Fernandez Caldas et al. (1980) usaram, entretanto, a mesma abreviatura para simbolizar o $\mathrm{pH}$ no qual a adsorção líquida de $\mathrm{H}^{+} \mathrm{e}$ $\mathrm{OH}^{-}$é nula

\section{Outras representações}

Espinoza et al. (1975) afirmam que, como os solos contêm uma mistura de minerais secundários de argila contendo carga negativa constante e óxidos e argilominerais com cargas dependentes de $\mathrm{pH}$, seria correto usar o termo PCZ "aparente" da mistura, e não somente PCZ, como nos casos de determinações em óxidos puros.

$\mathrm{O}$ termo $\Delta \mathrm{pH}_{\mathrm{PCZ}}$ foi sugerido (Hendershot et al. 1979) para representar a diferença entre o ponto de carga zero e $0 \mathrm{pH}$ medido em KCl $1 \mathrm{~mol} \mathrm{~L}^{-1}$, como indicativo da medida do desenvolvimento pedogenético de determinado solo. Stoop (1980) representou como $\mathrm{pH}^{0}$ o valor de $\mathrm{pH}$ no qual a carga superficial é nula.

Wann \& Uehara (1978) e Uehara (1988) utilizaram o termo $\mathrm{pH}_{0}$ para representar $0 \mathrm{pH}$ no qual a carga líquida variável é zero, sendo resultante da adsorção de $\mathrm{H}^{+}$e $\mathrm{OH}^{-}$, e obtido na intersecção das curvas de titulação de um determinado sal. Esta simbologia foi usada também por Tessens \& Zauyah (1982) e Zhang et al. (1989). Outros autores (Gillman, 1984; Gillman \& Sumner, 1987; Gangaiya \& Morrison, 1987; Singh \& Uehara, 1998) utilizaram o termo $\mathrm{pH}_{0}$ para representar 0 $\mathrm{pH}$ no qual o potencial superficial e, conseqüentemente, a densidade de carga variável é nula.

Morais et al. (1976) utilizaram o termo PCZ para definir um ponto obtido após a medição da adsorção de íns de diferentes sais, como, $\mathrm{KCl}, \mathrm{MgCl}_{2}, \mathrm{MgSO}_{4}, \mathrm{~K}_{2} \mathrm{SO}_{4}$, enquanto que Magalhães \& Page (1984b) propuseram um método chamado de "equilíbrio" mas chamaram de PCZ o ponto obtido nesse método, da mesma maneira como haviam chamado esse ponto quando utilizaram a titulação potenciométrica e a retenção iônica.

\section{PCZ: Modelos de Previsão}

O primeiro modelo de previsão, proposto por Parks $(1965,1967)$, é baseado no modelo de eletrovalência de Pauling e recebeu a denominação de modelo eletrostático. O modelo se baseia em um equilíbrio entre sítios positivos e negativos na superfície do sólido envolvendo $\mathrm{H}^{+}$da seguinte forma:

$$
\mathrm{M}-\mathrm{O}^{-}+2 \mathrm{H}^{+} \Leftrightarrow \mathrm{M}-\mathrm{OH}_{2}^{+}
$$

Nesse equilíbrio assume-se que o importante é o trabalho eletrostático ganho pela aproximação dos $2 \mathrm{H}^{+}$ a $\mathrm{M}-\mathrm{O}$. Levando-se em consideração que efeitos do campo cristalino aumentam a estabilidade da ligação $\mathrm{M}$ $\mathrm{OH}$, chega-se às seguintes equações para sólidos de metal de número de coordenação 6:

$$
\begin{aligned}
P C Z=A-B(Z / R)-C(E E C C) \\
P C Z=A_{\text {ef. }}-11,5[Z / R+0,0029(E E C C) \\
P C Z=18,6-11,5[Z / R+0,0029(E E C C)+a] \\
\\
\quad \text { e fazendo-se } \\
(Z / R)_{\text {ef. }}=[Z / R+0,0029(E E C C)+a] \\
P C Z=18,6-11,5(Z / R)_{\text {ef. }} \\
P C Z=16,5-11,5(Z / R)_{\text {ef. }}
\end{aligned}
$$

Em que $A, a, B$ e $C$ são constantes, $A_{\text {ef. }}$ leva em consideração o efeito de estabilização do campo cristalino (EECC), e (Z/R) ét. é a relação ajustada para a estabilização do campo cristalino da valência $Z$ do metal $\mathrm{M}$ e à soma $\mathrm{R}$ do raio desse metal com o diâmetro do oxigênio. A equação (10) representa os óxidos anidros e (11) os hidratados. Parks (1965) salienta que para óxidos anidros e hidratados de metais com número de coordenação 4, a constante A da equação deve ser substituída por valores de 16,0 e 13,9, respectivamente.

A equação (10) prediz que o PCZ deve variar linearmente com a relação $Z / R$, aumentando à medida em que $Z / R$ diminui. A equação também estabelece a importância da valência e do raio do metal constituinte da estrutura dos minerais controlando a acidez da superfície e, conseqüentemente, o PCZ. Assim, minerais que têm na sua estrutura metais com alta valência e pequeno raio iônico têm grupamentos funcionais $\mathrm{OH}$ mais ácidos que minerais com metais de mais baixa valência e maior raio iônico. Esse comportamento é o resultado da distribuição de densidade eletrônica do oxigênio da hidroxila em direção ao metal de alta valência e raio pequeno, ao mesmo tempo que existe um enfraquecimento da ligação covalente $\mathrm{O}-\mathrm{H}$ com a conseqüente ionização mais fácil do $\mathrm{H}$ (McBride, 1989). Por esse raciocínio, pode-se ordenar os principais cátions estruturais dos minerais do solo da seguinte forma quanto a capacidade de atrair a nuvem eletrônica dos elementos próximos:

$$
\mathrm{Si}>\mathrm{Al}>\mathrm{Fe}
$$

Esses cátions, nessa ordem, têm maior capacidade de atrair a nuvem eletrônica dos oxigênios 
aos quais estão em contato, especialmente os de superfície, provocando uma ionização mais fácil do $\mathrm{H}$ da hidroxila. A diferenciação do Si para $\mathrm{Al}$ e $\mathrm{Fe}$ se faz pela valência e raio, ao passo que entre $\mathrm{Al}$ e $\mathrm{Fe}$ a diferenciação se faz pelo raio iônico.

Devido à dificuldade de predição do $\mathrm{PCZ}$ de alguns óxidos e de silicatos, Yoon et al. (1979) desenvolveram um modelo para corrigir os problemas encontrados com a utilização das equações propostas por Parks $(1965,1967)$. O modelo proposto combina a química cristalina com a teoria eletrostática da protonação, sugerindo que esta deve ser representada do ponto de vista cristalográfico pela adição de prótons a um oxigênio em movimento com carga residual $v$ da seguinte forma:

$\mathrm{M}-\mathrm{O}^{(2 \cdot v)-}+2 \mathrm{H}^{+} \Leftrightarrow \mathrm{M}^{v+}-\mathrm{OH}_{2}$

Em que $v$ representa a força de ligação eletrostática de Pauling. A equação parcial do modelo é:

$P C Z=A-B(v / L)-0,5 \log [(2-v) / v]$

Em que $A$ e $B$ são constantes semelhantes às do modelo anterior e podem ser obtidas por regressão, $v$ é igual a $\mathrm{Z} /{ }_{N C}$, valência dividida pelo número de coordenação do metal estrutural e $L$ é o comprimento da ligação metalhidroxila. Em termos práticos, $L$ pode ser calculado pela soma $L^{\prime}+r$, em que $L^{\prime}$ pode ser representado pela média do comprimento da ligação $\mathrm{M}-\mathrm{O}$ no interior do cristal e $r$ pode ser tomado como $0,101 \mathrm{~nm}$, que é a distância de $\mathrm{O}-\mathrm{H}$ no gelo e muito próximo da distância da ligação O$\mathrm{H}$ em água, hidróxidos e sólidos hidratados (Yoon et al., 1979). A equação final se torna:

$P C Z=18,43-53,12(v / L)-0,5 \log [(2-v) / v]$

ou

$P C Z=18,43-53,12\left[(v / L)+5,61 \times 10^{-4} \mathrm{C}\right]-0,5 \log [(2-v) / v]$

Em que $C$ é a energia de estabilização do campo cristalino, termo utilizado apenas para os metais de transição. Esse modelo deu resultados consistentes para alguns óxidos ou hidróxidos mas não conseguiu explicar bem o PCZ para óxidos ou hidróxidos com ligações de ponte hidrogeniônicas fortes, o que é uma limitação para alguns dos principais minerais do solo (White \& Zelazny, 1986).

Como o PCZ calculado dessa forma ainda deixava algumas discrepâncias entre valores calculados e medidos, Sverjensky (1994) apontou que deveria existir um efeito adicional não levado em consideração no modelo eletrostático/química cristalina de protonação de superfície, que é associado com a solvatação de prótons em solução aquosa. De acordo com esse autor, a semelhança da adsorção de prótons superficiais com adsorção de cátions superficiais, representada pelas equações (16) e (17):
$\mathrm{M}-\mathrm{O}+\mathrm{H}^{+} \Leftrightarrow \mathrm{M}-\mathrm{OH}$

$\mathrm{M}-\mathrm{O}+\mathrm{Ct}^{++} \Leftrightarrow \mathrm{M}-\mathrm{O} \mathrm{Ct}^{+}$

em que $\mathrm{Ct}^{+}$é o cátion trocável, sugere que a aplicação da teoria da solvatação de Born para adsorção de cátions (Sverjensky, 1993) pode ser importante nas reações de protonação de superfície. Desenvolvendo seu modelo, Sverjensky (1994) chegou à equação para o cálculo de PCZ:

$\mathrm{PCZ}=-0,5(\Delta \Omega \gamma / 2.303 \mathrm{RT})\left(1 /_{\mathrm{ek}}\right)-\mathrm{B}\left(\mathrm{s} /{ }_{\mathrm{MM}-\mathrm{OH}}\right)+\log \mathrm{K}_{\mathrm{H}}{ }^{+}$

em que $\Delta \Omega \gamma$ é o termo de solvatação de Born, ck é a constante dielétrica para o sólido, $\mathrm{B}\left(\mathrm{S} \mathrm{YM}_{\mathrm{YH}}\right)$ corresponde a $B(v / L)$, já definidos anteriormente, e logK" ${ }_{H}^{+}$é uma constante de equilíbrio. Segundo Sverjensky (1994), o primeiro termo na equação refere-se à contribuição da solvatação, que depende muito das propriedades do sólido $\left(1 / /_{\varepsilon k}\right)$, o segundo termo refere-se à repulsão eletrostática dos prótons superficiais pelo metal imediatamente abaixo da superfície e o termo final é uma combinação da constante geral de ligação intrínseca para - próton na superfície do sólido com a parte remanescente da contribuição da solvatação que depende das constantes dielétricas da água na interface e na solução, e da atração eletrostática do próton ao oxigênio de superfície.

Utilizando oito minerais como padrão e suas propriedades, o autor simplificou a equação (18) em:

$P C Z=21,1158\left(1 / /_{\text {ck }}\right)-42,9148\left(\mathrm{~s} / /_{\text {M-OH }}\right)+14,6866$

e postula que, com ela, pode-se predizer o PCZ de outros óxidos utilizando-se os valores de constante dielétrica e valores de força de ligação eletrostática de Pauling e o comprimento da ligação metal hidroxila.

Embora os resultados sejam consistentes e de concordância muito próxima entre os PCZs calculados e medidos (Sverjensky, 1994), algumas dúvidas ainda persistem. O valor utilizado pelo autor do PCZ medido para a gibbsita, e muito importante para dar validade ao modelo, é 9,84, mas Parks (1965), citando Schuylenborgh \& Sänger (1949), Schuylenborg (1951) e Koz'mina et al. (1963), observou que esses autores encontraram valores de PCZ entre 3,8 e 5,2 para amostras naturais e sintéticas de gibbsita. Esses valores não são contestados na literatura, sendo alguns deles, inclusive, utilizados por Stumm \& Morgan (1981), Stumm (1992) e Sparks (1995) para exemplificar a variação a que está sujeito o PCZ de minerais do solo.

O que parece ser um fator importante, e que será discutido adiante, é a incapacidade dos modelos de previsão existentes (Sparks, 1965; 1967; Yoon et al. 1979; Sverjensky, 1994) de captarem as variações de morfologia externa a que estão sujeitos os minerais do solo. Dessa forma, todos os minerais são tratados de maneira igual e como se apresentassem uma superfície externa semelhante, com os mesmos grupos funcionais em qualquer situação. 


\section{CARACTERIZAÇÃO E MEDIÇÃO DAS CARGAS}

Modelos baseados na teoria da dupla camada

A presença de cargas positivas e negativas caracterizando a natureza anfotérica de alguns solos foi demonstrada por Mattson (1927), há mais de setenta anos e por Schofield (1939) para as partículas de argila. Possivelmente, por não ser essa uma característica importante nos solos das regiões temperadas, o assunto ficou esquecido por algumas décadas.

Embora Schofield (1958) tenha aplicado a teoria da dupla camada de Gouy-Chapmann para solos e Parks \& de Bruyn (1962) e Parks (1965) tenham publicado importantes trabalhos na área de PCZ e PIE de óxidos sólidos, foi somente com o trabalho de Raij e Peech (1972) que se iniciou um período de renovado interesse pelo estudo das características da carga de superfície dos solos das regiões tropicais. Nesse trabalho, considerado o verdadeiro divisor de águas da Eletroquímica de Solos moderna, iniciou-se a aplicação de modelos matemáticos para estudar o comportamento das cargas de superfície. Nele, também se demonstrou que os minerais dominantes nos solos altamente intemperizados dos trópicos se comportavam essencialmente como os óxidos metálicos e apresentavam predominantemente cargas dependentes de $\mathrm{pH}$.

O ponto de partida para a utilização dos modelos matemáticos foi a utilização da teoria da dupla camada de cargas de Gouy-Chapmann, que descreve com sucesso várias propriedades dos colóides do solo, incluindo a carga elétrica de superfície (Singh \& Uehara, 1986). A equação final da teoria de Gouy-Chapmann relaciona a densidade de carga $(\sigma)$ com o potencial de superfície $(\psi)$ (Overbeek, 1952; Babcock, 1963; Adamson, 1967; van Olphen, 1977; Raij \& Peech, 1972) da seguinte forma:

$$
\sigma=\left(\frac{2 \mathrm{n} \varepsilon \mathrm{KT}}{\pi}\right)^{1 / 2} \operatorname{sen} \mathrm{h}\left(\frac{\mathrm{ze}}{2 \mathrm{KT}}\right) \psi \mathrm{O}
$$

em que $\sigma$ é a densidade de carga superficial, $\mathrm{n}$ é a concentração de eletrólitos, e é a constante dielétrica do meio, $\mathrm{K}$ é a constante de Boltzmann, T é a temperatura absoluta, z é a valência do íon saturante, e é carga do elétron e yo é o potencial de superfície. fazer:

Para um dado sal em solução aquosa, pode-se

$$
\frac{2 \varepsilon K T}{\pi}=A \text { e } \frac{z e}{2 K T}=B \quad A \text { e } B=\text { constantes e a }
$$

equação (20) reduzir-se-á a:

$\sigma=A(n)^{1 / 2} \operatorname{sen} h B$ \%o

que para um potencial de superfície muito pequeno transforma-se em

$$
\sigma=\left(\frac{\varepsilon \mathrm{K}}{4 \pi}\right) \Psi 0
$$

A equação simplificada (21) indica que, nos colóides de potencial de superfície constante, a densidade de carga varia com a concentração de eletrólitos do meio. Isso significa que se o potencial é constante, com uma mudança na força iônica da solução há mudança na densidade de carga para a manutenção da equação. Isso acontece nos solos de carga variável.

Além disso, para os colóides de potencial constante e, por extensão, para os solos de carga variável, a relação entre a concentração de íons determinantes de potencial e o potencial se faz por meio da equação de Nernst (van Olphen, 1977; Hunter, 1993):

$\psi \mathrm{O}=\frac{\mathrm{KT}}{\mathrm{ze}} \ln \frac{\left(\mathrm{H}^{+}\right)}{\left(\mathrm{H}^{+}\right)_{\mathrm{PCZ}}}$ ou $\quad \psi \mathrm{O}=\frac{\mathrm{KT}}{\mathrm{ze}} \ln \frac{\left(\mathrm{H}^{+}\right)}{\left(\mathrm{H}_{0}^{+}\right)}$

que, com as devidas substituições das constantes envolvidas, transforma-se em:

$\psi \mathrm{o}=59\left(\mathrm{pH}_{\mathrm{PCZ}}-\mathrm{pH}\right)$ ou $\psi \mathrm{o}=59(\mathrm{pHo}-\mathrm{pH}) \mathrm{mV}$ a $25^{\circ} \mathrm{C}$

A equação (24) permite calcular o potencial de superfície a qualquer $\mathrm{pH}$ desde que o PCZ seja conhecido.

Substituindo-se (24) em (20) têm-se:

$\sigma=\left(\frac{2 n K T}{\pi}\right)^{1 / 2} \operatorname{sen~} \mathrm{h}\left(\frac{\mathrm{ze}}{2 \mathrm{KT}}\right) 59\left(\mathrm{pH}_{\mathrm{PCZ}}-\mathrm{pH}\right)$

Com auxílio da equação (25) pode-se predizer, pelo menos qualitativamente, como a densidade de cargas varia com relação às características da suspensão. Quando o pH da suspensão se iguala ao PCZ do colóide, tanto o potencial superficial quanto a densidade de cargas são zero. Vê-se também que $\sigma$ aumenta positivamente conforme $0 \mathrm{pH}$ diminui abaixo do PCZ e $\sigma$ aumenta negativamente em função do aumento do $\mathrm{pH}$ acima do PCZ. Do mesmo modo as cargas positivas ou negativas aumentam ou diminuem com o aumento da concentração eletrolítica da solução, dependendo se $0 \mathrm{pH}$ da solução está abaixo ou acima do $\mathrm{PCZ}$, respectivamente. O gráfico de $\sigma$ em função do $\mathrm{pH}$ dá uma família de curvas para diferentes concentrações de eletrólitos com interseção no PCZ do colóide. Em síntese, esse foi o ponto de partida para utilizar a adição de ácidos e bases fortes sob diferentes concentrações de eletrólitos na solução, para determinar a densidade de cargas e o ponto de carga zero (PCZ) dos solos com predominância de colóides de carga variável.

A partir dessa data até hoje, diversos autores têm usado a técnica da titulação potenciométrica na determinação da carga superficial e dos chamados pHo, PCZ etc., de diversos solos (Gillman, 1974; El-Swaify e Sayegh, 1975; Espinosa et al., 1975; Gallez et al., 1976; Gillman \& Bell, 1976; Hendershot e Lavkulich, 1978; Parker et al., 1979; Costa et al., 1984; Magalhães \& Page, 1984; Marcano-Martinez \& McBride, 1989; 
Siqueira et al., 1990; Chaves \& Trajano, 1992; Alleoni \& Camargo, 1994a; Silva et al.,1996; Dynia \& Camargo, 1998). Essa metodologia encontra-se descrita em Camargo et al. (1986).

Parker et al. (1979) publicaram uma avaliação crítica da utilização da teoria do ponto de carga zero ao sistema solo. Nesse trabalho, eles utilizaram uma nova terminologia para o $\mathrm{pH}$ no qual uma série de curvas de titulação potenciométrica se interceptam e demonstraram que não necessariamente o encontro dessas curvas definiria o PCZ ou pHo. Eles chamaram esse pH de Ponto de Efeito Salino Zero (PESZ). O ponto de carga líquida zero foi determinado como sendo o $\mathrm{pH}$ no qual a adsorção de cátions e ânions se igualava e houve discrepância entre valores de PCLZ e PESZ. A adsorção específica de catíons, a troca de $\mathrm{H}^{+}$com contraíons associados com carga permanente e o consumo do ácido ou base adicionados em reações paralelas secundárias nas quais o consumo de $\mathrm{H}^{+}$ou $\mathrm{OH}^{-}$pode não significar uma mudança na carga de superfície, são algumas razões apontadas para justificar as discrepâncias dos valores. Os autores enfatizaram que cuidados devem ser tomados ao se utilizarem os valores obtidos pela interseção das curvas para se fazer predições. A nomenclatura sugerida por Parker et al. (1979) passou a ser adotada por vários autores (Rojas \& Adams, 1980; Tessens \& Shamshuddin,1982; Madrid et al., 1984; Schulthess \& Sparks, 1986; Meijer \& Buurman, 1987; Toner IV et al., 1989; Zhang et al., 1989).

A constatação de que a maior parte dos solos nos trópicos tem na sua composição colóides com predomínio de cargas variáveis levou Uehara \& Gillman (1980) e Gillman \& Uehara (1980) a apresentarem um modelo que relaciona a densidade de carga superficial com o potencial de superfície para sistemas híbridos. Nesse modelo, a densidade de carga líquida total de superfície em um sistema misto é:

$\sigma_{\mathrm{T}}=\sigma_{\mathrm{p}}+\sigma_{\mathrm{v}}$

Em que $\sigma_{p}$ é a densidade de carga dos colóides com carga permanente e por isso mesmo constante e $\sigma_{v}$ é a densidade de cargas dos colóides com carga variável.

Introduzindo-se algumas modificações na equação 20, de Gouy-Chapmann, apresentada anteriormente têm-se:

$\sigma_{\mathrm{v}}=\left(\frac{2 \mathrm{ncKT}}{\pi}\right)^{1 / 2} \operatorname{sen} \mathrm{h} 1,15 \mathrm{z}(\mathrm{pHo}-\mathrm{pH})$

$\sigma_{\mathrm{T}}=\sigma_{\mathrm{p}}+1,67 \times 10^{-6} \mathrm{n}^{1 / 2}\left(\mathrm{pH}_{0}-\mathrm{pH}\right)$

Essa equação mostra que há dois pontos de carga zero, um para $\sigma_{\mathrm{T}}=0$ e outro para $\sigma_{\mathrm{v}}=0$. O ponto de carga zero da mistura é expresso como ponto de carga líquida zero (PCLZ)

$\sigma_{p}+\sigma_{v}=0$
Para um eletrólito indiferente do tipo 1:1, para valores de $\mathrm{pH}-\mathrm{pH}_{0}$ menor que a unidade $\mathrm{e}$ considerando que nessas condições senh1,15z( $\left.\mathrm{pH}_{0}-\mathrm{pH}\right)$ $\approx 1,15\left(\mathrm{pH}_{\circ}-\mathrm{pH}\right)$ (Uehara e Gillman, 1980), e substituindo-se as constantes por seus valores na equação (28), tem-se:

$\sigma_{\mathrm{T}}=\sigma_{\mathrm{p}}-0,135 \mathrm{n}^{1 / 2}\left(\mathrm{pH}_{0}-\mathrm{pH}\right)$

ou ao $\mathrm{pH}$ correspondente a PCLZ:

$\sigma_{\mathrm{p}}=-0,135 \mathrm{n}^{1 / 2}\left(\mathrm{pH}_{0}-\mathrm{pH}\right)$

e assim, a correspondência entre os dois pontos de carga zero fica:

$P C L Z=\left(\sigma_{p} / 0,135 n^{1 / 2}\right)+p H_{\circ}$

em que $\mathrm{pH}_{0}$ é uma propriedade intrínseca da mistura e o PCLZ depende da concentração de eletrólitos, n, a menos que $\sigma_{p}=0$.

Nesse modelo, $\mathrm{pH}_{0}$ é obtido pelo ponto de interseção de duas ou mais curvas obtidas pela titulação potenciométrica a diferentes concentrações de eletrólito, de acordo com a metodologia de Parks \& Bruyn (1962) e Raij \& Peech (1972). A carga permanente $\left(\sigma_{\mathrm{p}}\right)$ é medida pela diferença entre a adsorção de cátions e ânions no $\mathrm{pH}_{0}$ determinado na ausência de adsorção específica de íons. Se a adsorção de cátions excede a de ânions, a carga permanente é negativa e se o inverso ocorre, $\sigma_{p}$ é positiva. O PCLZ corresponde ao $\mathrm{pH}$ no qual a adsorção de cátions e ânions é igual (Gillman e Uehara, 1980). Em ambos os casos, utiliza-se, basicamente, a metodologia de adsorção de cátions e ânions em função do $\mathrm{pH}$, como descrita originalmente por Schofield (1949).

Wada \& Okamura (1983), usando uma formulação teórica diferente, também chegaram a dois valores de pontos de carga zero aos quais chamaram PCZ e PCC (ponto de carga constante), que equivale, essencialmente, ao PCLZ e $\mathrm{pH}_{0}$, respectivamente.

\section{Modelos Baseados no Balanço de Cargas}

Um passo importante e com enfoque diferente no estudo das cargas superficiais de partículas coloidais de solos foi proposto por Sposito (1981). Esse autor preconizou o estudo do balanço de cargas por meio de uma lei geral da conservação que não exige modelo químico de superfície, como a teoria da dupla camada de cargas. Esse balanço de cargas se aplica a qualquer tipo de solo, tanto os com predominância de minerais de carga permanente quanto aqueles com maioria dos minerais de carga variável, desde que apresentem uma interface com cargas elétricas.

A equação geral do balanço de cargas pode ser expressa como a soma de diversas densidades de carga (Sposito, 1981; 1983; 1984; 1989b; 1992) e a carga total da partícula pode ser representada matematicamente pela equação:

$\sigma_{\mathrm{p}}=\sigma_{\mathrm{o}}+\sigma_{\mathrm{H}}+\sigma_{\mathrm{EI}}+\sigma_{\mathrm{EE}}$ 
Em que $\sigma_{p}$ é a densidade de carga da partícula, $\sigma_{o}$ é a densidade de carga líquida estrutural permanente, $\sigma_{H}$ é a densidade de carga protônica líquida, $\sigma_{\mathrm{EI}}$ é a densidade de carga líquida devida a íons que formam complexos de esfera interna e $\sigma_{\mathrm{EE}}$ é a densidade de carga líquida devida a íons que formam complexos de esfera externa.

\section{Carga Estrutural Permanente}

A carga estrutural permanente $\left(\sigma_{0}\right)$ é aquela criada pela substituição isomórfica na estrutura dos minerais e já definida anteriormente.

\section{Carga Protônica}

Carga protônica líquida $\left(\sigma_{H}\right)$ é a diferença entre mols de prótons e mols de íons hidroxila complexados por grupos funcionais de superfície e, conceitualmente, os prótons encontrados na parte difusa da dupla camada de cargas não são incluídos em $\sigma_{H}$ (Sposito, 1989; 1992). Esse componente do balanço de cargas é essencialmente dependente do $\mathrm{pH}$, pois com sua mudança haverá modificação na protonação ou desprotonação dos grupos funcionais de superfície dos minerais, causando mudança na densidade de cargas, ou seja, em $\sigma_{H}$. Além do $\mathrm{pH}$, a concentração de eletrólitos indiferentes ou a força iônica da solução afeta essa cargas. Valores de $\sigma_{H}$ podem ser positivos, negativos ou nulos. Valores máximos para os principais minerais de carga dependente de $\mathrm{pH}$ podem ser estimados a partir de dados cristalográficos e variam assim: goethita $-6,7$ a $+4,4$; gibbsita $-5,6$ a $+2,8$ e caulinita $-1,0$ a $+0,35$ $\mu \mathrm{mol} \mathrm{m}{ }^{-2}$ (Sposito, 1984).

\section{Carga de Complexos de Esfera Interna}

Carga líquida de complexos de esfera interna $\left(\sigma_{E I}\right)$ é a carga originária da presença de íons, exceto $\mathrm{H}^{+}$e $\mathrm{OH}^{-}$ , que formam complexos com os grupos funcionais superficiais, ligando-se diretamente à estrutura cristalina dos minerais. Essa carga tem origem na adsorção específica de alguns ânions como fosfato, sulfato, silicato etc. (Hingston et al., 1972; 1974; Jepson et al., 1976; Parfitt \& Atkinson, 1976; Parfitt \& Smart, 1978; Wann \& Uehara, 1978; Martin \& Smart, 1987; McBride, 1989) e de cátions como $\mathrm{Cu}, \mathrm{Pb}, \mathrm{Zn}, \mathrm{Cd}, \mathrm{Ni}$, etc. (Kinniburgh et al., 1976; Bowden et al.,1977; McBride,1994).

\section{Carga de Complexos de Esfera Externa}

A carga líquida de complexos de esfera externa origina-se de íons que se localizam na camada de Stern, próximos da superfície das partículas mas sem a interferência estrutural. Íons como $\mathrm{Al}^{3+}, \mathrm{Ca}^{2+}, \mathrm{Mg}^{2+}$, $\mathrm{SO}_{4}^{2-}$ etc. são importantes na formação desse tipo de carga.

\section{Carga Difusa}

Como os sistemas coloidais são sempre eletricamente neutros, se a carga das partículas $\left(\sigma_{\mathrm{p}}\right)$ na equação (33) é diferente de zero, ela tem que ser balanceada. Isso se dá pela formação da densidade de carga difusa $\left(\sigma_{D}\right)$, que é a carga desenvolvida pelos íons na parte difusa da dupla camada de cargas. Essas cargas movem-se quase que livremente em solução, mas perto o suficiente para balancear $\sigma_{\mathrm{p}}$. Assim:

$$
\begin{aligned}
& \sigma_{o}+\sigma_{H}+\sigma_{E I}+\sigma_{E E}+\sigma_{D}=0 \\
& \sigma_{p}+\sigma_{D}=0 \Rightarrow \sigma_{p}=-\sigma_{D}
\end{aligned}
$$

Se a densidade de carga é expressa em mols de carga por unidade de massa, a carga líquida dos íons adsorvidos é:

$$
\left(q_{+}-q_{-}\right)=\sigma_{E l}+\sigma_{E E}+\sigma_{D}
$$

em que q se refere ao excesso de carga superficial de cátions e ânions. Em algumas aplicações, é útil agruparem-se os componentes do balanço de carga (Sposito, 1992) como:

$\sigma_{\text {in }}=\sigma_{o}+\sigma_{H}$

na qual $\sigma_{\text {in }}$ é a densidade de carga superficial intrínseca ou aquela inerente à partícula.

\section{Pontos de Carga Zero}

Em função do balanço de cargas, alguns pontos de carga zero podem ser definidos, dependendo do tipo de densidade de carga que é colocada em questão. Fontes (1996) propõe uma terminologia unificada para distinguir os diferentes tipos de PCZs (TABELA 1).

TABELA 1 - Símbolos, nomes e condições para os diferentes tipos de PCZ definidos em função do balanço de cargas.

\begin{tabular}{lll}
\hline Símbolo Nome & Condição \\
\hline PCZ & Ponto de Carga Zero & $\sigma_{\mathrm{p}}=0$ ou $\sigma_{\mathrm{D}}=0$ \\
PCZL & $\begin{array}{l}\text { Ponto de Carga Zero } \\
\text { Líquida }\end{array}$ & $\sigma_{\mathrm{in}}=0$ ou $\Delta \mathrm{q}=0$ \\
PCZPL & $\begin{array}{l}\text { Ponto de Carga Zero } \\
\text { Protônica Líquida }\end{array}$ & $\sigma_{\mathrm{H}}=0$ \\
PCZES & $\begin{array}{l}\text { Ponto de Carga Zero por } \\
\text { Efeito Salino }\end{array}$ & $\left(\frac{\partial \sigma_{\mathrm{H}}}{\partial \mathrm{l}}\right)_{\mathrm{T}}=0$
\end{tabular}

Fonte: Fontes (1996).

A tentativa de uniformizar os nomes prende-se ao fato de que todos são pontos nos quais diferentes tipos de carga deixam de existir ou se igualam a zero. $\mathrm{Na}$ realidade, Zero deveria funcionar como adjetivo e indicar uma qualidade do substantivo Líquida ou Protônica Líquida, fazendo com que Ponto de Carga Líquida Zero e Ponto de Carga Protônica Líquida Zero sejam mais corretos em termos de linguagem. Contudo, a estrita obediência às regras gramaticais pode, muitas vezes, tornar os termos científicos mais prolixos ou menos impactantes e, com isso, diminuir o poder de sua mensagem. Existe, portanto, um conflito entre a expressão técnica e a gramatical, sendo válida a criação ou adaptação do termo técnico sempre que necessário para facilitar a expressão (Prof. Nestor Kämpf, comunicação pessoal ao primeiro autor). 
Apenas o PCZES difere um pouco dos outros porque, na realidade, o que se iguala a zero é a variação da carga protônica líquida em relação à variação da força iônica da solução, sob temperatura constante. A terminologia PCZES não é invalidada porque essa invariância de $\sigma_{H}$ é conseqüência da variação de cargas em colóides anfotéricos que caracterizam uma condição de igualdade a zero.

A terminologia para o termo PCZES difere da apresentada por Alleoni \& Camargo (1993) e Camargo \& Alleoni (1996), que propõem o termo Ponto de Efeito Salino Nulo (PESN). Segundo esses autores, o nome Ponto de Efeito Salino Nulo, define o valor de $\mathrm{pH}$ no ponto de interseção de duas ou mais curvas de titulação, visto que, nestas condições, parece mais adequado o uso do adjetivo nulo, que indica uma qualidade do efeito do sal, do que do numeral zero, muito usado na literatura, para definir o ponto. Segundo Sposito (1989), o PESN é estritamente um valor de $\mathrm{pH}$ no qual a carga líquida do próton (diferença entre o número de moles de $\mathrm{H}^{+}$e $\mathrm{OH}^{-}$adsorvidos) é invariável com a concentração do sal, e não um ponto no qual a carga superficial é nula, como preconizaram Parks \& Bruyn (1962).

Alternativamente, então, a simbologia apresentada no TABELA 2 pode ser utilizada.

TABELA 2 - Símbolos, nomes e condições para os diferentes tipos de PCZ definidos em função do balanço de cargas.

\begin{tabular}{lll}
\hline Símbolo Nome & Condição \\
\hline PCZ & Ponto de Carga Zero & $\sigma_{\mathrm{p}}=0$ ou $\sigma_{\mathrm{D}}=0$ \\
PCLZ & $\begin{array}{l}\text { Ponto de Carga Líquida } \\
\text { Zero }\end{array}$ & $\sigma_{\text {in }}=0$ ou $\Delta \mathrm{q}=0$ \\
PCPLZ & $\begin{array}{l}\text { Ponto de Carga Protônica } \\
\text { Líquida Zero }\end{array}$ & $\sigma_{\mathrm{H}}=0$ \\
PESN & $\begin{array}{l}\text { Ponto de Efeito Salino } \\
\text { Nulo }\end{array}$ & $\left(\frac{\partial \sigma_{\mathrm{H}}}{\partial l}\right)_{T} 0$ \\
\hline
\end{tabular}

Fonte: Sposito (1984;1989b;1992); Alleoni \& Camargo(1993); Camargo \& Alleoni (1996).

\section{Metodologia para Medir PCZs e $\sigma_{\mathrm{s}}$}

Com base no desenvolvimento teórico do balanço de cargas, Sposito e diversos colaboradores vêm desenvolvendo uma metodologia que permite a medição da carga estrutural permanente $\left(\sigma_{0}\right)$ (Anderson \& Sposito, 1991) e a medição simultânea da densidade de carga protônica $\left(\sigma_{H}\right)$ em conjunto com a adsorção de cátions e ânions (Charlet \& Sposito, 1987; 1989; Chorover \& Sposito, 1995).

A medição da carga estrutural permanente $\left(\sigma_{0}\right)$ baseia-se na alta seletividade que 0 íon $\mathrm{Cs}^{+}$tem para com as argilas 2:1 em função da formação de complexos de esfera interna nos poros ditrigonais das superfícies siloxonas desses minerais. Essa seletividade é aumentada no sistema onde o cátion trocador é o $\mathrm{Li}^{+}$e a secagem do material adsorvente aumenta a força de formação do complexo de esfera interna entre o $\mathrm{Cs}^{+}$e a carga estrutural do mineral. Após a secagem, promove-se uma troca iônica com $0 \mathrm{Li}^{+}$ (LiCl) para retirar o $\mathrm{Cs}^{+}$dos grupos funcionais hidroxila e por último remove-se $\circ \mathrm{C}_{\mathrm{s}}^{+}$adsorvido por troca com - $\mathrm{NH}_{4}{ }^{+}$que tem capacidade de penetrar nos poros ditrigonais das superfícies siloxanas (Anderson \& Sposito, 1991).

Esse método tem sido usado com sucesso por Anderson \& Sposito (1991), Chorover \& Sposito (1995), Fontes \& Sposito (1995) e Peixoto et al. (1995a) em solos brasileiros. Fontes \& Sposito (1995), utilizando amostras de horizontes B de Latossolos, e por isso com muito pouco $C$ orgânico, observaram que o método permite a detecção de pequenas quantidades de minerais com carga permanente, muitas vezes em quantidades não detectáveis pela difração de raios- $X$. Peixoto et al. (1995a), por sua vez, utilizaram amostras de horizontes $A_{1}, A_{3}$ e $B_{2}$ de Latossolos e observaram que a M.O. foi uma possível fonte de erros, superestimando os valores de $\sigma_{o}$, principalmente dependendo do tipo de cátion naturalmente complexado pela M.O. Apesar disso, eles afirmaram que, pela lógica da amostragem e pela natureza dos solos, foi possível detectar e isolar o efeito da M.O. nas cargas do solo e estimar as cargas negativas permanente $\left(\sigma_{o}\right)$, variável $\left(\sigma_{\text {var }}\right)$, da matéria orgânica $\left(\sigma_{\mathrm{MO}}\right)$ e total acessível ao $\mathrm{Cs}^{+}$ $\left(\sigma_{\mathrm{TOT}}\right)$. Recentemente, Chorover et al. (1999) mediram a carga estrutural acessível ao $\mathrm{Cs}^{+}$em uma cronoseqüência de solos havaianos e observaram que essa carga aumentou inicialmente com a idade dos solos para depois decrescer à medida que o intemperismo atuava nos solos mais velhos. Observaram também que a magnitude da retenção de $\mathrm{Cs}^{+}$correlacionou-se positivamente com a presença de minerais 2:1 detectados pela difratometria de raios- $X$.

A medição da densidade de carga protônica foi desenvolvida inicialmente por Charlet \& Sposito (1987) e se baseia no fato da titulação potenciométrica, introduzida ao estudo de solos por Raij \& Peech (1972), não medir a densidade de carga protônica a um dado $\mathrm{pH}$ e força iônica, mesmo que se assuma que não ocorram reações paralelas secundárias, como dissolução de minerais. Na realidade, a titulação potenciométrica produz um valor de $\sigma_{H}$ relativo aquele do solo no começo da titulação e que é chamado de $\sigma_{\text {Haparente }}$. Por isso, a obtenção do PCZES ou PESN pelo cruzamento das curvas de $\sigma_{H}$ e pH a diferentes forças iônicas não permite assumir que esse ponto equivale ao PCZPL. Assim, foi desenvolvida uma metodologia experimental para se medir, simultaneamente, a titulação potenciométrica e a adsorção de cátions e ânions para se construirem curvas renormalizadas de $\sigma_{H}$ vs pH para determinar PCZPL e PCZES, em solos de carga permanente próxima a zero (Charlet \& Sposito, 1987). Pode-se também estabelecer uma relação entre estes dois atributos como já mostrado na equação (30) (Zhang \& Zhao, 1997). 
A densidade de carga protônica líquida a cada pH e força iônica (I) é calculada pela equação:

$\sigma_{\mathrm{H}_{(\mathrm{pH}, \mathrm{I})}}=\sigma_{\mathrm{HTit}(\mathrm{pH}, \mathrm{I})}-\sigma_{\mathrm{HTit}}(\mathrm{PCZPL}, \mathrm{l})$

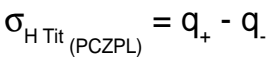

em que $\sigma_{\mathrm{Htit}(\mathrm{pH}, \mathrm{I})}$ é a densidade de carga protônica líquida aparente, ou seja, o valor relativo à densidade de carga protônica que existia no ponto zero de titulação, e $\sigma_{\mathrm{HTit}(\mathrm{PCZPL})}$ é a densidade de carga protônica líquida aparente no $\mathrm{pH}$ igual ao PCZPL. É comum igualar-se $\sigma_{\mathrm{HTit}}$ a $\sigma_{H}$, o que é correto apenas se a densidade de carga protônica líquida é igual a zero quando a titulação potenciométrica começa. Desde que $\sigma_{0} \cong 0,0 \mathrm{pH}=$ PCZPL pode ser obtido experimentalmente de modo independente da titulação potenciométrica pela adsorção de ânions e cátions (Charlet \& Sposito, 1987; Sposito, 1992).

Esse método foi melhorado por Anderson \& Sposito (1992) pela introdução da medição independente de $\sigma_{\circ}$ e, como conseqüência, abre-se a possibilidade de se trabalhar em solos que apresentam ao mesmo tempo carga permanente e carga variável. Agora, determina-se o $\sigma_{0}$ pela adsorção seletiva do $\mathrm{Cs}^{+} \mathrm{e}$, da mesma forma anterior, calcula-se $0 \sigma_{\mathrm{H}}$ a partir do $\sigma_{\mathrm{H} \text { aparente }}$ obtido pela titulação potenciométrica:

$$
\begin{aligned}
& \sigma_{\mathrm{H}_{(\mathrm{pH}, \mathrm{I})}}=\sigma_{\mathrm{HTit}}{ }_{(\mathrm{pH}, \mathrm{I})}-\sigma_{\mathrm{HTTt}}{ }_{(\mathrm{PCZPL}, \mathrm{I})} \\
& \sigma_{\mathrm{HTit}}{ }_{(\mathrm{PCZPL}, \mathrm{I})}=\left(q_{+}-\mathrm{q}_{.}\right)+\sigma_{\mathrm{o}}+\sigma_{\mathrm{HTit}}{ }_{(\mathrm{pH}, \mathrm{I})}
\end{aligned}
$$

Outro avanço no método foi apresentado por Chorover \& Sposito (1993, 1995), no qual ainda se observa o princípio do balanço de cargas, o uso da titulação potenciométrica e os dados de adsorção de cátions e ânions, mas levando-se em consideração dois aspectos diferentes. Primeiro, foi inserida uma correção para as reações paralelas secundárias, que podem consumir prótons sem que a densidade de cargas da superfície se modifique. Essa preocupação já havia sido levantada por diversos autores (Hohl \& Stumm, 1976; Parker et al., 1979; Marcano-Martinez \& McBride, 1989). Em segundo lugar, em cada experimento de titulação potenciométrica, a leitura do eletrodo de $\mathrm{pH}$ foi calibrada em termos de concentração de $\mathrm{H}^{+}$, ao invés de atividade de $\mathrm{H}^{+}$, para se evitar a necessidade do uso de um modelo de coeficiente de atividade (Chorover \& Sposito, 1995).

$\mathrm{Da}$ mesma forma que apresentado anteriormente:

$$
\begin{aligned}
& \sigma_{\mathrm{H}\left(-\log \mathrm{H}^{+}, \mathrm{I}\right)}^{+}=\sigma_{\left.\mathrm{H} \text { Tit(- } \log \mathrm{H}^{+}, \mathrm{I}\right)}-\sigma_{\mathrm{H} \text { Tit (PCZPL, I) }} \\
& \sigma_{H\left(-\log H_{+}, \mathrm{l}\right)}=-\left[\left(q_{+}-q_{-}\right)+\sigma_{0}\right] \\
& \sigma_{H \text { Tit }(P C Z P L, ~ I)}=\left(q_{+}-q_{-}\right)+\sigma_{0}+\sigma_{H \text { Tit }\left(-\log H_{+}, \mathrm{l}\right)}
\end{aligned}
$$

Essa metodologia foi utilizada por Chorover \& Sposito (1995), Peixoto et al. (1995b) para solos brasileiros e Schroth \& Sposito (1997) para caulinita padrão com resultados satisfatórios, dando condições de determinar os pontos de carga zero líquida e protônica líquida (PCZL e PCZPL) e as seguintes densidades de carga: estrutural permanente $\left(\sigma_{0}\right)$; protônica líquida $\left(\sigma_{H}\right)$ e dos íons adsorvidos líquida $(\Delta \mathrm{q})$. Em alguns solos a metodologia permite a visualização do PCZES e, por isso, a possibilidade da comparação desse com o PCZPL (Chorover \& Sposito, 1995). Peixoto et al. (1995a,b) consideraram que o conjunto de métodos precisa ser melhorado tanto na medição do $\sigma_{\circ}$ quanto de $\sigma_{H}$ e $\Delta q$. Segundo esses autores, os problemas encontrados referem-se a complexação do $\mathrm{Cs}^{+}$pela M.O. na determinação do $\sigma_{0}$, e, quanto ao método da titulação, esse seria mais susceptível a erros, devido a reações secundárias, e as correções da hidrólise do Al poderiam exagerar esses erros. Mas os autores salientam que caso os valores extremos de $\mathrm{pH}$ sejam evitados, esses problemas podem ser minimizados.

\section{RELAÇÃO ENTRE CARGAS E MINERAIS DO SOLO}

$\mathrm{Na}$ caracterização e na medição das cargas superficiais das partículas dos solos altamente intemperizados, tem-se, invariavelmente, dado importância menor à mineralogia dos principais componentes desses solos. Com respeito a esse fato, Greenland \& Mott (1978) assim se expressaram: "Em geral parece que a forma mineralógica de um óxido, oxihidróxido ou hidróxido particular é de importância relativamente pequena na medição do PCZ. Isso acontece porque todas as superfícies dos óxidos tendem a se hidratar rapidamente, de modo que na condição úmida que prevalece no solo, todas as superfícies são hidratadas, e quartzo $\left(\mathrm{SiO}_{2}\right)$, hematita $\left(\alpha-\mathrm{Fe}_{2} \mathrm{O}_{3}\right)$ e coríndon $\left(\alpha-\mathrm{Al}_{2} \mathrm{O}_{3}\right)$ têm superfícies essencialmente iguais àquelas da sílica gel $\left(\mathrm{SiO}_{2} \cdot \mathrm{nH}_{2} \mathrm{O}\right)$, da goethita $(\alpha$ - $\mathrm{FeOOH})$ e da gibbsita $\left(\mathrm{Al}(\mathrm{OH})_{3}\right)$ ". Entretanto, atualmente sabe-se que esse raciocínio não é válido e que, na realidade, todos esses minerais apresentam variações específicas do mais importante grupamento funcional exposto nas suas bordas e faces externas, a hidroxila. As especificidades relativas a tamanho de partículas, superfícies expostas, planos superficiais etc. tornam importante o estudo individualizado de cada um desses minerais.

\section{Caulinita}

A caulinita é um mineral argiloso silicatado formado pelo empilhamento de unidades cristalográficas constituídas de uma lâmina tetraedral de silício e oxigênios e uma lâmina octaedral de alumínio e hidroxilas (Figura 3). A ligação das unidades se dá por pontes hidrogeniônicas, o que limita o mineral à possibilidade de expandir-se e expor suas superfícies internas. Com isso o mineral tem capacidade de reagir e apresentar cargas apenas nas faces externas e nas 
bordas quebradas (Jackson, 1965; Greenland \& Mott, 1978; Dixon, 1989).

O plano de átomos de oxigênio em uma das superfícies externas da caulinita é chamado superfície siloxana (Greenland \& Mott, 1978; Sposito, 1984) e é caracterizado por uma simetria hexagonal distorcida, dando origem ao chamado poro ditrigonal (Dixon, 1989) cuja reatividade depende da natureza e da distribuição de carga eletrônica na camada silicatada. Se não existe substituição isomórfica de cátions vizinhos para criar déficit de carga positiva, a cavidade siloxana funciona como um fraco doador de elétrons que atrai somente moléculas dipolares neutras, como por exemplo, a água. Se existe substituição isomórfica e excesso de carga negativa, torna-se possível a formação de complexos tanto com cátions trocáveis quanto com moléculas dipolares, principalmente se a substituição ocorre na camada tetraedral. $\mathrm{O}$ outro plano externo na superfície da caulinita é o plano de hidroxilas ligadas aos átomos de alumínio da camada dioctaedral que apresenta cada hidroxila ligada a dois átomos de alumínio. Essa superfície é chamada de superfície gibbsítica.

Greenland \& Mott (1978) e Stumm (1992) discutiram, de forma ligeiramente divergente, a existência de três planos morfológicos de diferentes composições na parte externa da caulinita, que induzem à formação de cargas elétricas e grupamentos $\mathrm{OH}$ envolvidos nas reações de protonação e desprotonação da superfície. $\mathrm{Na}$ superfície gibbsítica existem os grupos $\mathrm{Al}-\mathrm{OH}-\mathrm{Al}$, nas bordas ou faces os grupos $\mathrm{Al}-\mathrm{OH}$ e,ou $\mathrm{Si}-\mathrm{OH}$, e na superfície siloxana a carga permanente devido à

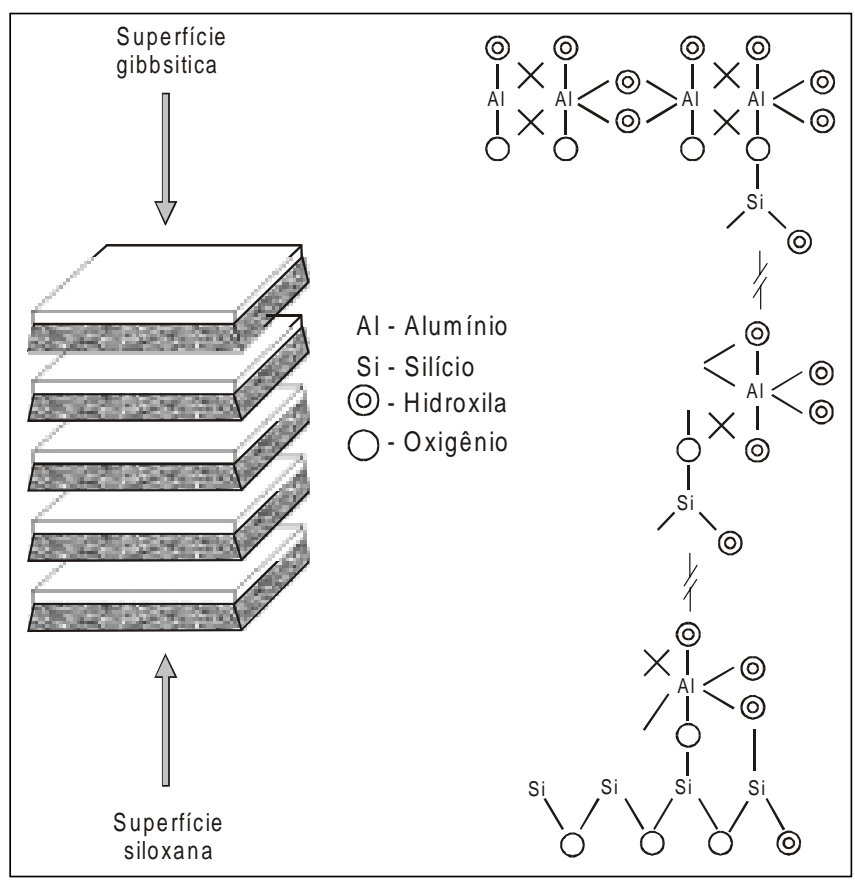

Figura 3 - Representação idealizada da estrutura da caulinita mostrando suas diferentes superfícies e suas diversas possibilidades de bordas conforme as faces expostas (Fontes, 1996). substituição isomórfica. Com relação a esses grupos, Greenland \& Mott (1978) salientaram que dois aspectos do trabalho de Schofield \& Samson (1954) têm recebido pouca atenção: o fato de os grupos $\mathrm{OH}$ da superfície gibbsítica aparentemente não desenvolverem carga positiva e o fato do acréscimo na carga negativa em função do $\mathrm{pH}$ ser maior que o explicado pelas cargas das bordas. A razão apontada por Greenland \& Mott (1978) é que a caulinita é formada em ambiente rico em sílica e que a adsorção de silicatos pela face gibbsítica explicaria essas peculiaridades. Fontes (1996) propõe a hipótese de que o grupo Al-OH-Al da face gibbsítica já está com suas cargas balanceadas de tal modo que a possibilidade da hidroxila receber $u \mathrm{H}^{+}$adicional é muito pequena, o que explicaria além do não desenvolvimento da carga positiva nessa superfície, o acréscimo da carga negativa com o aumento do $\mathrm{pH}$, mais que a possibilidade de desenvolvimento de carga nas bordas. A crítica que se faz a textos como os de Greenland \& Mott (1978) e Stumm (1992) é que eles não discutem a diferenciação das faces em relação às bordas dos cristais de caulinita e como essa diferenciação pode provocar o aparecimento de diferentes grupamentos hidroxila de superfície, o que, definitivamente, influi no desenvolvimento das cargas.

De acordo com Evangelou (1998), até $50 \%$ das cargas negativas da caulinita podem ser conseqüência de desprotonação de oxigênio e hidroxilas terminais a $\mathrm{pH}$ alto $(\mathrm{pH} \approx 7,0)$. Todavia, Ma \& Eggleton (1999) mostraram que a carga das arestas quebradas e planos de $\mathrm{OH}$ expostos, ao invés de substituição $\mathrm{Al} / \mathrm{Si}$, é que determina a CTC da caulinita, mesmo no ponto de carga zero. Sendo assim, as cargas negativas de desprotonação de oxigênio e hidroxilas terminais seguramente seriam em maior proporção que $50 \%$.

White \& Zelazny (1986) apresentaram uma discussão geral sobre a morfologia externa de argilas silicatadas, incluindo algumas considerações sobre a caulinita. Segundo esses autores, as faces mais importantes dos minerais $1: 1$ seriam as (001), (100), (010), (110) e (1 10$)$, destacando-se obviamente, a importância das faces (001), uma das quais essencialmente local de cargas permanentes. Para as faces (010), que são locais de carga variável, eles postularam que elas expõem para cada unidade de área acsen $\beta$ (área da face 010 em função dos parâmetros de cela unitária) uma ligação tetraédrica não compartilhada e duas ligações octraédricas não compartilhadas, o que significa uma $\mathrm{Si}-\mathrm{OH}$ e duas $\mathrm{Al}_{\mathrm{OH}}^{\mathrm{OOH}}$, respectivamente. Nas faces $(110)$ e $(1 \overline{1} 0)$ existe uma assimetria com um lado apresentando $\mathrm{Si}-\mathrm{OH}$ e Al-OH mas o outro apresentando $\mathrm{Si}-\mathrm{OH}, \mathrm{Si}-\mathrm{OH}-\mathrm{Al}$ e Al-OH. Esses autores fizeram considerações sobre o pKa dos grupos $\mathrm{Al}-\mathrm{OH}$, mas não fizeram menção ao possível pKa para grupos Al-OH-Al, importantes por serem uma face inteira (001) na caulinita.

Ponto importante a ser lembrado é que a maioria dessas informações são obtidas utilizando-se minerais 
padrão e não minerais do solo. Isso se torna um problema na medida em que esses minerais podem ser bem diferentes. Singh \& Gilkes (1992) mostraram que caulinitas de 35 solos australianos foram caracterizadas como muito pobremente cristalizadas; apresentaram valores maiores para superfície específica e CTC e maior capacidade de adsorção de fosfatos comparadas com uma caulinita padrão. Além disso, elas apresentaram cristais menores e irregularmente arredondados comparadas aos cristais maiores, de faces bem formadas e perfeitamente hexagonais da caulinita padrão.

\section{Goethita}

Oxihidróxido de ferro, genericamente chamado de óxido de $\mathrm{Fe}$, a goethita é um dos minerais argilosos mais encontrados em solos de clima tropical e em quase todos os tipos de solos nas mais diversas regiões climáticas do globo. Nos locais onde predomina, a goethita imprime aos solos a coloração amarela ou bruna bastante encontrada nos solos brasileiros.

A estrutura da goethita consiste em planos de átomos de oxigênio e hidroxila em empacotamento denso hexagonal ao longo do eixo $\mathrm{X}$ com os íons $\mathrm{Fe}^{3+}$ ocupando $2 / 3$ dos sítios octaedrais e arranjados em correntes duplas ao longo do eixo Z. As correntes duplas adjacentes, dentro de uma mesma camada, são separadas por duas fileiras de sítios octaédricos vazios. Os sítios ocupados e os vagos se alternam em camadas sucessivas levando a uma simetria ortorrômbica. Nessa estrutura cristalográfica, podem ser distingüidos três tipos de grupo $\mathrm{OH}$ de superfície, conforme sua coordenação com um, dois ou três átomos de ferro (Russel et al., 1974; Parfitt et al., 1975; Parfitt \& Russel, 1977): hidroxila tipo $\mathrm{A}$ ou hidroxila de coordenação simples, tipo $\mathrm{C}$ ou de coordenação dupla e tipo B ou de coordenação tripla (Figura 4). Existe ainda um quarto tipo que é o grupo geminado onde dois grupos $\mathrm{OH}$ se ligam a um átomo de ferro (Cornell \& Schwertmann, 1996).

Em função desses vários tipos de hidroxila, a morfologia e as faces expostas desse mineral são importantes no desenvolvimento de cargas em ambiente aquoso. $\mathrm{O}$ grupamento $\mathrm{OH}$ possui um par de elétrons junto com um átomo de hidrogênio dissociável, o que permite reagir tanto com ácidos quanto com bases, dando aos óxidos de ferro, em geral, um caráter anfótero. Parfitt et al. (1975) indicaram que as faces importantes da goethita seriam as (100) e (010), provavelmente por estarem mais preocupados com a adsorção de fosfato, que se dá preferencialmente pela hidroxila de coordenação simples. Com base em estudos de espectroscopia infravermelha, detectou-se que as reações de adsorção se dão apenas nas ligações tipo $A$, sendo que as dos tipos $B$ e $C$ são relativamente bem menos reativas (Russel et al., 1974; Lewis \& Farmer, 1986). Schulze (1982) estudando uma série de goethitas sintéticas sugeriu que as faces (110) e (120) seriam bem desenvolvidas e que, provavelmente, as faces (021) ou

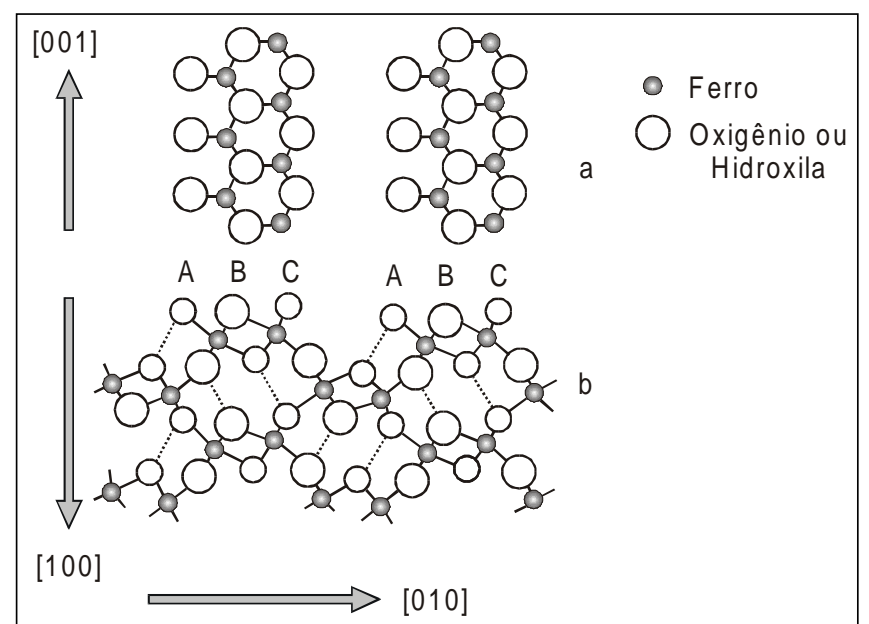

Figura 4 - Plano (a) e seção (b) da face (100) da goethita. A, C e B são grupos $\mathrm{OH}$ de coordenação simples, dupla e tripla, respectivamente (Segundo Russel et al., 1974).

(111) e (121) também, o que concordaria com estudos que mostraram as faces de macrocristais de goethita. White \& Zelazny (1986) indicaram que as faces mais prováveis são (100), (010) e (110) e que dessas a (010) é a que apresenta maior carga, baseado em cálculos teóricos. Barrón \& Torrent (1996) salientaram que as faces (100), (010), (110) e (021) são as mais comuns para goethitas sintéticas e de solos.

A maioria dos estudos parte da utilização de goethitas sintéticas que, de modo geral, têm morfologia acicular e, conseqüentemente, maior expressão para faces como (100), (010) e (110). Mas o que se observa para goethitas do solo é que as formas isodimensionais podem ser predominantes (Schwertmann \& Kämpf, 1985; Schwertmann \& Latham, 1986; Torrent et al., 1990; Fontes \& Weed, 1991; Netto, 1996) e assim, outras faces podem se tornar importantes no desenvolvimento de carga desses minerais.

\section{Hematita}

Verdadeiramente óxido de ferro, a hematita é importante mineral argiloso componente de solos de regiões tropicais e subtropicais. É menos encontrado que a goethita por não aparecer com muita expressão em solos de regiões temperadas e frias. É responsável pela coloração vermelha dos solos, já tendo sido encontrada correlação positiva entre avermelhamento do solo e teor de hematita (Santana, 1984; Fontes, 1988; Torrent et al., 1993).

Estruturalmente, a hematita consiste em planos de átomos de oxigênio em empacotamento denso hexagonal do tipo $A B A B$... em seqüência ao longo do eixo cristalográfico Z. Íons $\mathrm{Fe}^{3+}$ ocupam 2/3 dos espaços octaedrais, onde cada Fe é rodeado por seis oxigênios, e cada oxigênio é compartilhado por quatro íons de $\mathrm{Fe}^{3+}$.

Cristais sintéticos de hematita produzidos em condições semelhantes às de formação pedogenética normalmente exibem morfologia hexagonal, geralmente menos expressa em hematitas de solo (Schwertmann \& 
Taylor, 1989). Em solos, a morfologia da hematita pode variar de formas mais laminares, possivelmente ligadas a melhores condições de cristalização, a formas mais isodimensionais, provavelmente relacionadas com ambientes menos propícios a melhor cristalização (Fontes \& Weed, 1991). Em termos de faces expostas, de acordo com Kostov (1968), as faces usualmente descritas para cristais macroscópicos de hematita são: face basal (001), quase basal (104) e não basais (101), (110), (012), (223) e (247). Parfitt et al. (1975) indicaram que as faces dominantes em hematitas naturais são as (100) e $(10 \overline{1}$ 0),como se fossem duas faces distintas. $\mathrm{Na}$ realidade, as notações (100) e (10 $\overline{1}$ 0) são variantes que expressam a mesma face conforme se utiliza 0 sistema de notação de Bravais-Miller com 3 ou 4 eixos cristalógraficos para o sistema hexagonal.

Por outro lado, White \& Zelazny (1986) postularam que a face (001) seria a face mais importante, apresentando apenas hidroxilas de dupla coordenação e que seria uma face relativamente inerte. Apenas outras faces menos importantes teriam a possibilidade de sítios ativos em termos de reações de superfície. Barron \& Torrent (1996) indicam que as faces mais comuns para hematitas naturais e sintéticas são as (100), (110), (012), (104), (018), (113) e (001).

Morfologia laminar ou isodimensionais e tipos de faces expostas da hematitas podem ser determinantes nas reações de superfície e no desenvolvimento de carga pela exposição de diferentes tipos de hidroxilas.

\section{Gibbsita}

A gibbsita é um mineral não silicatado formado pelo empilhamento da unidade básica constituída por dois planos de hidroxila em empacotamento denso com o íon $\mathrm{Al}^{3+}$ em forma de sanduiche (Figura 5). O Al aparece em $2 / 3$ dos espaços octaedrais e são distribuídos formando anéis hexagonais. Estruturalmente, cada Al compartilha seis hidroxilas com outros três átomos de $\mathrm{Al}$, fazendo com que cada hidroxila seja dividida por dois átomos de alumínio (Hsu, 1989).

Os hidróxidos de Al, em geral, e a gibbsita, em particular, tendem a exibir crescimento maior na direção $X-Y$ e crescimento limitado, por acúmulo vertical, na direção Z. Isso é atribuído à forte ligação Al-OH-Al dentro da lâmina dioctaedral e à ligação relativamente fraca de pontes hidrogeniônicas entre as lâminas. Assim, gibbsita bem cristalizada freqüentemente se apresenta em lâminas hexagonais (Hsu, 1989). Neste caso, o desenvolvimento de carga e as reações de superfície serão governadas pela protonação ou desprotonação de hidroxilas de coordenação dupla, características das faces (001).

De acordo com White \& Zelazny (1986), as faces de equilíbrio para a gibbsita são os (001), (100), (110) e $(1 \overline{1} 0)$, com a primeira sendo mais importante, e as outras secundárias. Eles ainda salientaram que a face (001) não é carregada, e as outras faces têm uma

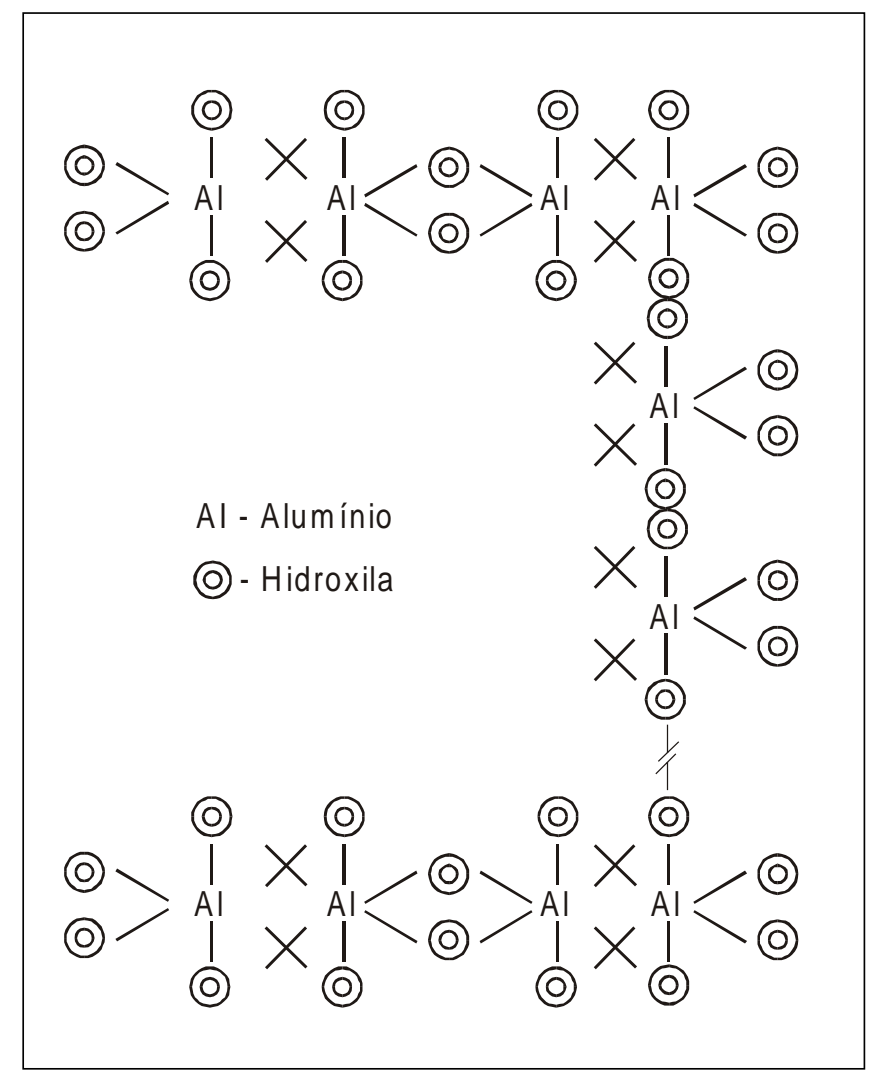

Figura 5 - Representação idealizada da estrutura da gibbsita mostrando as superfícies externas e as bordas (Fontes, 1996).

estrutura na qual um a cada dois Al de superfície apresentam dois grupamentos hidroxila de coordenação simples.

O modelo estrutural proposto para a gibbsita permite supor que os íons $\mathrm{Al}^{3+}$ localizado nas bordas dos anéis $\mathrm{Al}_{6}(\mathrm{OH})_{12}$ manifestará sempre uma carga positiva de superfície. Duas moléculas de água poderão ser retidas em posição de coordenação neste local. Estes sítios constituem o grupamento aluminol (AIOH). Outra possibilidade é a estrutura incluir três anéis de $\mathrm{Al}_{6}(\mathrm{OH})_{12}$, com dois octaedros de alumínio adicionais que estão ligados à estrutura por meio de pontes simples de $(\mathrm{OH})_{2}$. $\mathrm{Se}$ as arestas do cristal de gibbsita realmente incluem íons $\mathrm{Al}^{3+}$, que não são parte da estrutura do anel, então estes dois íons de $\mathrm{Al}^{3+}$ poderão representar também um sítio potencial de adsorção com dupla carga positiva (Goldberg et al., 1995).

As informações com relação à gibbsita de solos não são muitas, mas Mesquita Filho \& Torrent (1993) relataram a presença de cristais de gibbsita de morfologia subarredondada e com diâmetro médio de 75 $\mathrm{nm}$ em solos brasileiros. Netto (1996) encontrou, em diversos solos brasileiros, cristais de gibbsita provavelmente de morfologia prismática. Nessa situação as bordas terão muito maior influência nas reações de superfície e desenvolvimento de carga pela maior presença de hidroxilas de coordenação simples. 


\section{Densidade de Sítios Superficiais}

Além da morfologia e das faces expostas dos minerais, uma característica intrinsecamente ligada às cargas das partículas do solo é a densidade de sítios superficiais para os diversos minerais.

Devido à dificuldade de medir experimentalmente a densidade de sítios superficiais, cálculos teóricos utilizando as estruturas e hábitos cristalinos têm sido cada vez mais usados para se chegar a estes valores.

Barrón \& Torrent (1996) estudaram a configuração das hidroxilas de superfície da goethita e da hematita sob a premissa de que as propriedades de superfície dos óxidos e hidróxidos dependem de sua configuração superficial hidroxílica. Eles calcularam a densidade de hidroxilas de coordenação simples, dupla e tripla nas várias faces desses minerais e encontraram que ambos exibem diferenças marcantes entre faces, particularmente com respeito à presença e proporção de hidroxilas de coordenação simples, dupla e tripla. Além disso, pares de hidroxilas de coordenação simples, que estão envolvidas em adsorção específica de fosfato e outros íons, ocorrem em todas as faces da goethita, mas não em todas faces da hematita. De acordo com esses autores, a configuração de hidroxilas superficiais variável nas faces deve resultar em diferenças marcantes na adsorção de prótons e nas propriedades de carga superficial.

Por outro lado, Rustad et al. (1996), com método baseado em cálculos teóricos de estática molecular de ligação de prótons à superfície da goethita, mostraram que as faces da goethita não diferem significativamente e que, em geral, teriam uma densidade de sítios de adsorção reativos na faixa de 15 a 16 sítios $\mathrm{nm}^{-2}$ para os cristais dominados por faces (110) e (021). Trabalhando ainda nessa linha, Felmy \& Rustad (1998) postularam que os cálculos de estática molecular combinados com a relação de energia livre linear entre as energias da superfície hidroxilada e a superfície solvatada aquosa indicariam que as constantes de acidez para a maioria dos sítios simples, dupla ou triplamente coordenados têm valores semelhantes.

Koretsky et al. (1998) desenvolveram um método de estimativa dos tipos de sítios e de suas densidades ionizáveis na superfície mineral por meio da consideração de superfícies cristalinas ideais. Para cada mineral, utilizando alguns dos principais minerais dos solos, a clivagem ou o crescimento de faces predominantes foram estudados. Uma vez a superfície mineral, para um dado plano, tivesse sido escolhida, o número de sítios por unidade de área superficial era calculado usando cinco diferentes métodos. Para os minerais considerados, as densidades calculadas variaram de 0 a 40,8 sítios $\mathrm{nm}^{-2}$, amplitude consideravelmente maior que a de 2,3 a 10,0, normalmente citada na literatura.

\section{CONSIDERAÇÕES FINAIS}

A mineralogia típica dos solos altamente intemperizados, constituída basicamente de caulinita e óxidos de $\mathrm{Fe}$ e $\mathrm{Al}$, afeta processos físico-químicos importantes nos solos, como dispersão e floculação de colóides (Rengasamy et al., 1984;Goldberg \& Glaubig, 1987; Fontes et al., 1995), troca de cátions e ânions (Barber \& Rowell, 1972; Fey \& Le Roux, 1976; Gillman, 1980; Stoop, 1980) e adsorção de ânions, especialmente fosfato (Bigham et al., 1978; Mesquita Filho \& Torrent, 1993; Fontes \& Weed, 1996). Esses processos, por sua vez, são dependentes, em maior ou menor escala, de características da carga superficial desenvolvida pelos colóides do solo. Além disso, as determinações dos diversos pontos de carga zero e das diversas densidades de carga podem ser utilizadas para se fazer inferências a respeito do desenvolvimento pedogenético (Hendershot \& Lavkulich, 1978), da definição de cronoseqüência (Hendershot et al., 1979) e do comportamento quanto à dissolução de minerais (Chorover \& Sposito, 1995), entre outras aplicações. Sendo assim, a melhoria da capacidade preditiva dos diversos pontos de carga zero e densidades de carga superficial é condição imprescindível para o avanço da eletroquímica de solos.

Torna-se também fundamental estabelecer uma melhor ligação entre $\mathrm{PCZ}$ e adsorção de fosfato. $\mathrm{Na}$ medida em que a adsorção de fosfato se dá nas hidroxilas de coordenação simples (Russel et al., 1974; Parfitt et al., 1975; Parfitt \& Russel, 1977; Parfitt, 1978), pode-se inferir que, para um mesmo mineral, adsorverá mais fosfato aquele que apresentar maior PCZ. Essa inferência se baseia no fato de que o mineral de maior PCZ tem na sua constituição faces nas quais existe maior número de hidroxilas de coordenação simples em detrimento das de coordenação dupla ou tripla. Isso significa, pelo menos potencialmente, maior adsorção de fosfato. De acordo com Russel et al. (1974); Parfitt et al. (1975); Parfitt \& Russel, (1977); e Parfitt, (1978) o grupamento $\mathrm{OH}$ de coordenação simples é o mais reativo, e aqueles grupamentos $\mathrm{OH}$ de coordenação dupla e tripla parecem ser relativamente inertes. De acordo com Fontes (1996), isso se aplica bem à adsorção de diversos ânions, especialmente a do fosfato, provavelmente porque o grupamento simples é o único grupamento efetivamente sujeito à protonação. Quando essa acontece, existe o enfraquecimento da ligação covalente do metal superficial com o oxigênio que, com isso, facilita a formação de ligação covalente entre o oxigênio do fosfato com o metal da superfície. $\mathrm{Na}$ hidroxila de coordenação simples, o desvio da nuvem eletrônica do oxigênio será maior em direção aos dois hidrogênios, enfraquecendo a ligação $\mathrm{M}-\mathrm{O}$, o que não acontece com a hidroxila de coordenação dupla e nem tripla, pela maior dificuldade dessas serem protonadas. 
Com relação à medição de $\mathrm{PCZs}$, as dificuldades de medi-los, para os minerais dos solos, tem que ser resolvidas pela melhoria e aperfeiçoamento dos métodos existentes e, a partir dos resultados, deverão ser desenvolvidos modelos que contemplem as especificidades dos minerais do solo. Os modelos existentes (Parks, 1965; Yoon et al., 1979; Sverjensky, 1994) não conseguem alcançar esse objetivo, principalmente porque muito poucos trabalhos nessa área têm mostrado uma caracterização mineralógica completa.

O ponto fundamental a ser enfocado é a caracterização morfológica aprofundada dos principais minerais do solo em termos de faces expostas e a conseqüente exposição de diferentes grupamentos hidroxila. Da mesma forma que existe uma ordem de ionização mais fácil do $\mathrm{H}$ do grupo $\mathrm{OH}$ ligado aos cátions $\mathrm{Si}>\mathrm{Al}>\mathrm{Fe}$ (McBride, 1989), deve haver maior facilidade de ionização do $\mathrm{H}$ das hidroxilas de coordenação tripla > dupla > simples. Em havendo essa maior facilidade de ionização, aqueles minerais que expõem faces nas quais a densidade de grupos hidroxila de coordenação tripla é maior terão PCZ mais baixo que aqueles que expõem faces mais densamente povoadas de grupos hidroxila de coordenação simples. Esse raciocínio encontra suporte nos trabalhos de Hiemstra et al. (1989a, 1989b), que postulam que mais de um tipo de OH superficial participa nas reações de adsorção de prótons na superfície dos óxidos. Na mesma linha, o estudo de Barrón \& Torrent (1996) indicou que o conhecimento detalhado da "configuração hidroxílica de superfície" (CHS), da hematita e da goethita pode gerar uma base adequada para interpretar a química de superfícies desses minerais, o que pode ser estendido a todos os outros minerais do solo. Por sua vez, Rustad et al. (1996) e Felmy \& Rustad (1998) discordaram desse raciocínio por não terem encontrado diferença grande de ionização dos diferentes tipos de hidroxila em goethita.

Aspecto importante é a utilização de amostras de solo, pela sua diversidade, pois, praticamente todos os minerais presentes apresentam-se sob diferentes morfologias. Formas tabulares, nas quais as faces (001) são as mais importantes, são características de alguns minerais enquanto que formas mais isodimensionais, prismáticas etc. são características de outros. No caso de formas tabulares, o número de faces expostas é mais reduzido, ao passo que nas formas mais isodimensionais as possibilidades de faces expostas são muitas e muito mais complexas.

O desafio a ser enfrentado pelos pesquisadores da área de Química e Mineralogia dos solos é o aprofundamento de estudos que visem a determinar as faces que aparecem, suas configurações hidroxílicas de superfície, suas densidades de sítios ionizáveis etc. para os principais minerais que comumente aparecem em solos altamente intemperizados.

\section{REFERÊNCIAS BIBLIOGRÁFICAS}

ADAMSON, A.W. Physical chemistry of surfaces. New York: John Wiley, 1967. 747p.

ALLEONI, L.R.F.; CAMARGO, O.A. Ponto de efeito salino nulo: proposição da nomenclatura. Boletim Informativo da Sociedade Brasileira de Ciência do Solo, v.18, p.5-10, 1993.

ALLEONI, L.R.F.; CAMARGO, O.A. Modelos de dupla camada difusa de Gouy-Chapman e Stern aplicados a Latossolos Acrícos paulistas. Scientia Agricola, v.51, p.315-320, 1994a.

ALLEONI, L.R.F.; CAMARGO, O.A. Potencial elétrico superficial e carga elétrica líquida de latossolos ácricos. Revista Brasileira de Ciência do Solo, v.18, p.181-185, 1994b.

ANDERSON, S.J.; SPOSITO, G. Cesium adsorption method for measuring accessible structural surface charge. Soil Science Society of America Journal, v.55, p.1569-1576, 1991.

ANDERSON, S.J.; SPOSITO, G. Proton surface charge density in soils with structural and $\mathrm{pH}$ dependent charge. Soil Science Society of America Journal, v.56, p.1437-1443, 1992.

ARNOLD, P.W. Soil Science and the search for unifying concepts. Journal of Soil Science, v.28, p.393-402, 1977.

BABCOCK, K.L. Theory of chemical properties of soil colloidal systems at equilibrium. Hilgardia, v.34, p.417-542, 1963.

BALASUBRAMANIAN, V.; KANEHIRO, Y. Surface charge of Hydrandepts and its relation to nitrate adsorption as affected by profile depth and dehidration. Journal of Soil Science, v.29, p.47-57, 1978.

BARBER, R.G.; ROWELL, D.L. Charge distribution and the cation exchange capacity of an iron-rich kaolinitic soil. Journal of Soil Science, v.23, p.135-146, 1972.

BARRÓN, V.; TORRENT, J. Surface hydroxil configuration of various crystal faces of hematite and goethite. Journal of Colloid and Interface Science, v.177, p.407-410, 1996.

BARROW, N.J. Reactions with variable-charge soils. Dordrecht: Martinus Nijhoff, 1987. 191p.

BELL, L.C.; GILLMAN, G.P. Surface charge characteristics and soil solution composition of highly weathered soils. In: ANDREW, C.S.; KAMPRATH, E.J. (Ed.) Mineral nutrition of legumes in tropical and subtropical soils. Melbourne: CSIRO, 1978. p.37-57.

BIGHAM, J.M.; GOLDEN, D.C.; BUOL, S.W.; WEED, S.B.; BOWEN, L.H. Iron mineralogy of well-drained Utisols and Oxisols: II Influence on color, surface area, and phosphate retention. Soil Science Society of America Journal, v.42, p.825-830, 1978.

BOWDEN, J.W.; POSNER, A.M.; QUIRK, J.P. Ionic adsorption on variable charge mineral surfaces. Theoretical-charge development and titration curves. Australian Journal of Soil Research, v.15, p.121-136, 1977.

CAMARGO, O.A.; ALLEONI, L.R.F. Alguns métodos e terminologias em eletroquímica de solos. In: ALVAREZ V., V.H.; FONTES, L.E.F.; FONTES, M.P.F. (Ed.) O solos nos grandes domínios morfoclimáticos do Brasil e o desenvolvimento sustentado. Viçosa: SBCS; UF, Depto. de Solos, 1996. p.475-484.

CAMARGO, O.A.; MONIZ, A.C.; JORGE, J.A.; VALADARES, J.M.A.S. Métodos de análise química, mineralógica e física de solos do Instituto Agronômico de Campinas. Campinas: Instituto Agronômico, 1986. 94p. (Boletim Técnico, 106)

CHARLET, L.; SPOSITO, G. Monovalent ion adsorption by an Oxisol. Soil Science Society of America Journal, v.51, p.1155-1160, 1987.

CHAVES, L.H.G.; TRAJANO, M.D.M. Determinação do ponto de carga zero e das cargas elétricas do horizonte Ap de solos do estado da Paraíba. Revista Brasileira de Ciência do Solo, v.16, p.415-418, 1992. 
CHOROVER, J.; SPOSITO, G. Measurement of surface charge components. Berkeley: University of California.1993. 48p. (Technical Reports, NSF grant EAR 9221258)

CHOROVER, J.; SPOSITO, G. Surface charge characteristics of kaolinitic tropical soils. Geochimica et Cosmochimica Acta, v.59, p.875-884, 1995.

CHOROVER, J.; DiCHIARO, M.J.; CHADWIDK, O.A. Structural charge and cesium retention in a chronosequence of Tephritic soils. Soil Science Society of America Journal, v.63, p.169-177, 1999.

COCHRANE, T.T.; SOUZA, D.M.G. Measuring surface charge characteristics in Oxisols and Ultisols. Soil Science, v.140, p.223-229, 1985.

CORNELL, R.M.; SCHWERTMANN, U. The iron oxides: structure, properties, reactions, occurrence and uses. New York: VHC, 1996. 573p.

COSTA, L.M.; MORAIS, E.I.; RIBEIRO, A.C.; FONSECA, S. Cargas elétricas de um Latossolo Vermelho-Amarelo com diferentes coberturas florestais. Revista Ceres, v.31, p.351-359, 1984.

DYNIA, J.F.; CAMARGO, O.A. Effects of liming, green manuring and phosphate addition on eletrochemical attributes of an Oxisol from Central Brasil. Communications in Soil Science and Plant Analysis, v.29, p.322-327, 1998.

EL-SWAIFY, S.A.; SAYEGH, A.H. Charge characteristics of an Oxisol and an Inceptisol from Hawaii. Soil Science, v.120, p.49-56, 1975.

ESPINOZA, W.; GAST, R.G.; ADAMS Jr., R.S. Charge characteristics and nitrate retention by two Andepts from South-Central Chile. Soil Science Society of America Journal, v.39, p.842-846, 1975.

EVANGELOU, V.P. Environmental soil and water chemistry: principles and applications. New York: John Wiley \& Sons, 1998. 564p.

FELMY, A.R.; RUSTAD, J.R. Molecular statics calculations of proton binding to goethite surfaces: Thermodynamic modeling of the surface charging and protonation of goethite in aqueous solution. Geochimica et Cosmochimica Acta, v.62, p.2531, 1998.

FERNANDEZ CALDAS, E.; GONZALEZ BATISTA, A.; HERNANDEZ MORENO, J. La tipologia de los suelos y sus características eletroquímicas. Anales de Edafologia y Agrobiologia, v.39, p.1835-1843, 1980.

FEY, M.W.; LeROUX, J. Electric charges on sesquioxidic soil clays. Soil Science Society of America Journal, v.40, p.359364, 1976.

FONTES, M.P.F. Iron oxides mineralogy in some Brazilian Oxisols. Raleigh, 1988. 175p. Tese (Ph.D.) - North Carolina State University.

FONTES, M.P.F. Carga elétrica superficial de partículas do solo. In: CONGRESSO LATINOAMERICANO DE CIÊNCIA DO SOLO, 13., Águas de Lindóia, 1996. Palestras. Águas de Lindóia: Sociedade Latinoamericana de Ciência do Solo, 1996. (CD-ROM)

FONTES, M.P.F.; SPOSITO, G. Medição da densidade de carga estrutural acessível em Latossolos brasileiros com diferentes mineralogias. In: CONGRESSO BRASILEIRO DE CIÊNCIA DO SOLO, 25., Viçosa, 1995. Resumos Expandidos. Viçosa: Sociedade Brasileira de Ciência do Solo, 1995. v.1. p.292-294

FONTES, M.P.F.; WEED, S.B. Iron oxides in selected Brazilian Oxisols: I. Mineralogy. Soil Science Society of America Journal, v.55, p.1143-1149, 1991.

FONTES, M.P.F.; WEED, S.B. Phosphate adsorption by clays from Brazilian Oxisols: relationships with specific surface area and mineralogy. Geoderma, v.72, p.37-51, 1996.
FONTES, M.P.F.; GJORUP, G.B.; ALVARENGA, R.C.; NASCIF, P.G.S. Calcium salts and mechanical stress effects on waterdispersible clay of Oxisols. Soil Science Society of America Journal, v.59, p.224-227, 1995.

GALLEZ, A.; HERBILLON, A.J. Surface and charge characteristics of selected soils in the tropics. Soil Science Society of America Journal, v.40, p.601-608, 1976.

GANGAIYA, P.; MORRISSON, R.J. A review of the problems associed with applying the terms surface charge and zero point of charge to soils. Communications in Soil Science and Plant Analysis, v.18, p.1431-1451, 1987.

GAST, R.G. Surface and colloid chemistry. In: DIXON, J.B.; WEED, S.B. (Ed.) Minerals in soil environments. Madison: Soil Science Society of America, 1977. p.27-73.

GILLMAN, G.P. The influence of net charge on water dispersible clays and sorbed sulfate. Australian Journal of Soil Research, v.12, p.173-176, 1974.

GILLMAN, G.P. Using variable charge characteristics to understand the exchangeable cation status of Oxisols. Australian Journal of Soil Research, v.22, p.71-80, 1984.

GILLMAN, G.P.; BELL, L.C. Surface charge characteristics of six weathered soils from tropical North Queensland Australian Journal of Soil Research, v.14, p.351-360, 1976.

GILLMAN, G.P.; SUMNER, M.E. Surface charge characterization and soil solution composition of four soils from the Southern Piedmont in Gerorgia. Soil Science Society of America Journal, v.51, p.589-594, 1987.

GILLMAN, G.P.; UEHARA, G. Charge characteristics of soils with variable and permanent charge minerals: II Experimental. Soil Science Society of America Journal, v.44, p.252-255, 1980.

GOLDBERG, S.; DAVIS, J.A.; HEM, J.D. The surface chemistry of aluminum oxides and hydroxides. In: SPOSITO, G. (Ed.) The enviromental chemistry of aluminum. Boca Raton: Lewis Publishers, 1995. p.271-332.

GOLDBERG, S.; GLAUBIG, R.A. Effect of saturating cation, $\mathrm{pH}$, and aluminum and iron oxide on the flocculation of kaolinite and montmorillonite. Clays and Clay Minerals, v.35, p.220-227, 1987.

GREENLAND, D.J.; MOTT, C.J.B. Surfaces of soil clay particles. In: GREENLAND, D.J.; HAYES, M.H.B. (Ed.) The chemistry of soil constituents. New York: Wiley-Interscience, 1978. p.321-354.

HENDERSHOT, W.H. Measurement technique effects on the value of zero point of charge and its displacement from zero point of titration. Canadian Journal Soil Science, v.58, p.439-422, 1978.

HENDERSHOT, W.H.; LAVKULICH, L.M. The use of ZPC to assess pedogenic development. Soil Science Society of America Journal, v.42, p.468-472, 1978.

HENDERSHOT, W.H.; SINGLETON, G.A.; LAVKULICH, L.M. Variation in surface charge characteristics in a soil chronosequence. Soil Science Society of America Journal v.43, p.387-389, 1979

HERBILLON, A.J. Introduction to the surface charge properties of iron oxides and oxidic soils. In: STUCKI, J.W.; GOODMAN B.A.; SCHWERTANN, U. (Ed.) Iron in soils and clay minerals. Boston: Reidel, 1988. p.251-264. (NATO Advanced Studies Institute, Série C., 217)

HIEMSTRA, T., VAN RIEMSDIJK, W.H.; BOLT, G.H. Multisite proton adsorption modeling at the solid/solution interface of (hydr)oxides: A new approach. I. Model description and evaluation of intrinsic reaction constants. Journal of Colloid and Interface Science, v.133, p.91-104, 1989a. 
HIEMSTRA T.; DE WIT, J.C.M.; VAN RIEMSDIJK, W.H. Multisite proton adsorption modeling at the solid/solution interface of (hydr)oxides: A new approach. II. Application to various important (hydr)oxides. Journal of Colloid and Interface Science, v.133, p.105-117, 1989b.

HINGSTON, F.J.; POSNER, A.M.; QUIRK, J.P. Anion desorption by goethite and gibbsite. II. Desorption of anions from hydrous oxide surfaces. Journal of Soil Science, v.25, p.16-26, 1974.

HINGSTON, F.J.; POSNER, A.M.; QUIRK, J.P. Anion desorption by goethite and gibbsite. I. The role of the proton in determining the adsorption envelopes. Journal of Soil Science, v.23, p.177-192, 1972.

$\mathrm{HOHL}, \mathrm{H}$.; STUMM, W. Interaction of $\mathrm{Pb}^{2+}$ with hydrous $\gamma-\mathrm{Al}_{2} \mathrm{O}_{3}$. Journal of Colloid and Interface Science, v.55, p.281-288, 1976.

HSU, P.H. Aluminum hydroxides and oxyhydroxides. In: DIXON, J.B.; WEED, S.B. (Ed.) Minerals in soil environments. Madison: Soil Science Society of America, 1989. p.331-378.

HUNTER, R.J. Introduction to modern Colloid Science. New York: Oxford University Press, 1993. 338p.

JACKSON, M.L. Chemical composition of soils. In: BEAR, F.E. (Ed.) Chemistry of the soil. New York: 1965. 515p. (American Chemical Society Monograph Series)

KINNIBURGH, D.G.; JACKSON, M.L.; SYERS, J.K. Adsorption of alkaline earth, transition, and heavy metal cations by hydrous oxide gels of iron and aluminum. Soil Science Society of America Journal, v.40, p.796-799. 1976.

KORETSKY, C.M.; SVERJENSKY, D.A.; SAHAI, N. A model of surface site types on oxide and silicate minerals based on crystal chemistry: implications for site types and densities, multi-site adsorption, surface infrared spectroscopy, and dissolution kinetics. American Journal of Science, v.298, p.349-438. 1998.

KOSTOV, I. Mineralogy. Edinburgh: Oliver \& Boyd, 1968.

LAVERDIÈRE, M.R.; WEAVER, R.M. Charge characteristics of spodic horizons. Soil Science Society of America Journal, v.41, p.505-510, 1977.

LEPSCH, I.F.; BUOL, S.W. Investigations in an Oxisol-Ultisol topossequence in São Paulo State, Brazil. Soil Science Society of America Proceedings, v.38, p.491-496, 1974.

LEWIS, D.G.; FARMER, V.C. Infrared adsorption of surface hydroxyl groups and lattice vibrations in lepidocrocite $(\mathrm{g}-\mathrm{Fe} \mathrm{OOH})$ and boehmite $(\gamma-\mathrm{Al}-\mathrm{OOH})$. Clay Minerals, v.21, p.93-100, 1986.

MA, C.; EGGLETON, R.A. Cation exchange capacity of kaolinite. Clays and Clay Minerals, v.47, p.174-180. 1999.

MADRID, L.; DIAZ, E.; CABRERA, F. Charge properties of mixtures of minerals with variable and constant surface charge. Journal of Soil Science, v.35, p.373-380, 1984.

MAGALHÃES, A.F.; PAGE, A.L. Características das cargas elétricas dos solos da Zona da Mata de Pernambuco: I. Determinação das cargas de superfície. Revista Brasileira de Ciência do Solo, v.8, p.173-177, 1984a.

MAGALHÃES, A.F.; PAGE, A.L. Características das cargas elétricas dos solos da Zona da Mata de Pernambuco: II. Avaliação comparativa entre métodos de determinação. Revista Brasileira de Ciência do Solo, v.8, p.179-182, 1984b.

MARCANO-MARTINEZ, E.; McBRIDE, M.B. Comparison of the titration and ion adsorption methods for surface charge measurement in Oxisols. Soil Science Society of America Journal, v.53, p.1040-1045, 1989.

MARTIN, R.R.; SMART, R.St.C. X-ray photoelectron studies of anion adsorption on goethite. Soil Science Society of America Journal, v.51, p.54-56, 1987.

MATTSON, S. Anionic and cationic adsorption by soil colloidal materials of varying $\mathrm{SiO}_{2} / \mathrm{Al}_{2} \mathrm{O}_{3}+\mathrm{Fe}_{2} \mathrm{O}_{3}$ ratio. In: INTERNATIONAL CONGRESS SOIL SCIENCE 1. , Washington, 1927. Transations. Washington, 1927. p.199-211.
McBRIDE, M.B. Environmental chemistry of soils. New York: Oxford University Press, 1994. 406p.

McBRIDE, M.B. Reactions controlling heavy metal solubility in soils. Advances in Soil Science, v.10, p.1-56, 1989b.

McBRIDE, M.B. Surface chemistry of soil minerals. In: DIXON, J.B.; WEED, S.B. (Ed.) Minerals in soil environments. Madison: Soil Science Society of America, 1989a. p.35-88.

MEIJER, E.L.; BUURMAN, P. Salt effect in a multicomponent variable charge system: curve of zero salt effect, registered in a pH-sat. Journal of Soil Science, v.38, p.239-244, 1987.

MEKARU, T.; UEHARA, G. Anion adsorption in ferrugionous tropical soil. Soil Science Society of America Proceeding, v.36, p.296-300, 1972.

MESQUITA FILHO, M.V.; TORRENT, J. Phosphate sorption as related to mineralogy of a hydrosequence of soils from the Cerrado region (Brazil). Geoderma, v.58, p.107-123, 1993.

MORAIS, F.E.; PAGE, A.L.; LUND, L.J. The effect of $\mathrm{pH}$, salt concentration, and nature of electrolytes on the charge characteristics of Brazilian tropical soils. Soil Science Society of America Journal, v.40, p.521-527, 1976.

NAIDU, R.; SYERS, J.K.; TILLMAN, R.W.; KIRKMAN, J.H. Effect of liming and added phosphate on charge characteristics of acid soils. Journal of Soil Science, v.41, p.157-164, 1990.

NETTO, A.R. Influência da mineralogia da fração argila sobre propriedades físico-químicas de solos brasileiros. Viçosa, 1996. 144p. Dissertação (Mestrado) - Universidade Federal de Viçosa.

OKAMURA, Y.; WADA, K. Electric charge characteristics of Ando(B) and Red Yellow B soil and weathered pumices. Journal of Soil Science, v.34, p.287-295, 1983.

OLPHEN, H. van. An introduction to clay colloid chemistry. New York: Jonh Wiley \& Sons, 1977. 318p.

OVERBEEK, J.Th.G. Electrochemistry of the double layer. In: KRUYT, H.R. (Ed.) Colloid science. Amsterdam: Elsevier, 1952. v.1, p.115-193.

PARFITT, R.L. Anion adsorption by soils and soil materials. Advances of Agronomy, v.30, p.1-50, 1978.

PARFITT, R.L.; ATKINSON, R.J.; SMART, R.St.C. The mechanisms of phosphate fixation by iron oxides. Soil Science Society of America Journal, v.39, p.837-841, 1975.

PARFITT, R.L.; ATKINSON, R.J. Phosphate adsorption on goethite $(\alpha-\mathrm{FeOOH})$. Nature, v.264, p.740-742, 1976.

PARFITT, R.L.; RUSSEL, J.D. Adsorption on hydrous oxides. IV. Mechanisms of various ions on goethite. Journal of Soil Science, v.28, p.297-305, 1977.

PARFITT, R.L.; SMART, R.St.C. The mechanism of sulfate adsorption on iron oxides. Soil Science Society of America Journal, v.42, p.48-50, 1978.

PARKER, J.C.; ZELAZNY, L.W.; SAMPATH, S.; HARRIS, W.G. $A$ critical evaluation of the extension of zero point of charge (ZPC) theory to soil systems. Soil Science Society of America Journal, v.43, p.668-673, 1979.

PARKS, G.A. The isoeletric points of solid oxides, solid hydroxides, and aqueous hidroxo complex systems. Chemical Review, v.65, p.177-198, 1965.

PARKS, G.A. Surface chemistry of oxides in aqueous systems. Advances in Chemistry Series, v.67, p.121-160, 1967.

PARKS, G.A.; BRUYN, P.L. The zero point of charge of oxides. Journal of Physical Science, v.66, p.967-973, 1962.

PEIXOTO, R.T.G.; TRAINA, S.J.; BIGHAM, J.M. Aplicabilidade do método de adsorção de Cs na determinação de carga elétrica permanente em Latossolos derivados de basalto no Paraná. In: CONGRESSO BRASILEIRO DE CIÊNCIA DO SOLO, 25., Viçosa, 1995. Resumos Expandidos. Viçosa: Sociedade Brasileira de Ciência do Solo, 1995a. v.1. p.295-297. 
PEIXOTO, R.T.G.; TRAINA, S.J.; BIGHAM, J.M. Propriedades químicas de superfície em função da composição mineral e matéria orgânica em Latossolos derivados de basalto no Paraná. In: CONGRESSO BRASILEIRO DE CIÊNCIA DO SOLO, 25., Viçosa, 1995. Resumos Expandidos. Viçosa: Sociedade Brasileira de Ciência do Solo, 1995b. v.1, p.298-300.

PÉREZ, D.V.; RAMOS, D.P.; NASCIMENTO, R.A.M.; BARRETO, W.O. Propriedades eletroquímicas de horizontes $B$ texturais. Revista Brasileira de Ciência do Solo, v.17, p.157-164, 1993.

PYMAN, M.A.F.; BOWDEN, J.W.; POSNER, A.M. The movement of titration curves in the in the presence of specific adsorption. Australian Journal of Soil Research, v.17, p.191-195, 1979.

RAIJ, B. VAN.; PEECH, M. Electrochemical properties of some Oxisols and Alfisols of the tropics. Soil Science Society of America Proceedings, v.36, p.587-593, 1972.

RAIJ, B. VAN. Determinação do Ponto de Carga Zero em solos. Bragantia, v.32, p.337-347, 1973.

RENGASAMY, P.; GREENE, R.S.B.; FORD, G.W. The role of clay fraction in the particle arrangements and stability of soil aggregates: a review. Clay Research, v.3, p.53-67, 1984.

ROJAS, J.L.; ADAMS, M.J. Efecto del cultivo sobre el punto de carga neta cero (PCNC) en tres suelos altamente intemperizados com aplicaciones de calcio e foforo. Agronomia Tropical, v.30, p.29-54, 1980.

RUSSEL, J.D.; PARFITT, R.L.; FRASER, A.R.; FARMER, V.C. Surface structures of gibbsite, goethite and phosphated goethite. Nature, v.248, p.220-221, 1974.

RUSTAD, J.R.; FELMY, A.R.; HAY, B.P. Molecular statics calculations of proton binding to goethite surfaces: A new approach to estimation of stability constants for multisite surface complexation models. Geochimica et Cosmochimica Acta, v.60, p.1563-1576, 1996.

SAKURAI, K.; OHDATE, Y.; KYUMA, K. Factors affecting zero point of charge (ZPC) of variable charge soils. Soil Science and Plant Nutrition, v.35, p.21-31, 1989.

SAKURAI, K.; TESHIMA, A.; KYUMA, K. Changes in zero point of charge (ZPC), specific surface area (SSA), and cation exchange capacity (CEC) of kaolinite and montmorillonite, and strongly weathered soils caused by Fe and Al coating. Soil Science and Plant Nutrition, v.36, p.73-81, 1990.

SANTANA, D.P. Soil formation in a toposequence of Oxisols from Patos de Minas region, MG State, Brazil. Purdue: 1984. 129p. Tese (Ph.D) - Purdue University.

SCHOFIELD, R.K. The electric charges on clay particles. Soils Fertility, v.2, p.1-5, 1939.

SCHOFIELD, R.K. Effect of $\mathrm{pH}$ on electric charges carried by clay particles. Journal Soil of Science, v.1, p.1-8, 1949.

SCHOFIELD, R.K. Influence of surface charges on the properties of porous material. In: EVERETT, D.H.; STONE, F.S. (Ed.) The structure and properties of porous materials. Londres: Butterworths, 1958. p.261-265.

SCHOFIELD, R.K.; SAMSOM, H.R. Flocculation of kaolinite due to the attraction of oppositely charged faces. Discussions of the Faraday Society, v.18, p.135-145, 1954.

SCHROTH, B.; SPOSITO, G. Surface charge properties of kaolinite. Clays and Clay Minerals, v.45, p.85-91. 1997.

SCHULTHESS, C.P.; SPARKS, D.L. Back titration technique for proton isotherm modelling of oxide surfaces. Soil Science Society of America Journal, v.50, p.1406-1411, 1986.

SCHULZE, G.D. The identification of iron oxides by differential $X$-ray diffraction and the influence of aluminum substitution on the structure of goethite. München: 1982. 167p. Tese (Doutorado) - Technischen Universität München.

SCHWERTMANN, U.; KÄMPF, N. Properties of goethite and hematite in kaolinitic soils of Southern and Central Brazil. Soil Science, v.139, p.344-350, 1985.
SCHWERTMANN, U.; LATHAM, M. Properties of iron oxides in some New Caledonian Soils. Geoderma, v.39, p.105-123, 1986.

SCHWERTMANN, U.; TAYLOR, R.M. Iron Oxides. In: DIXON, J.B.; WEED, S.B. (Ed.) Minerals in soil environments. 2.ed. Madison: Soil Science Society of America Books, 1989. p.379-438. (Serie, 1)

SILVA, M.L.N.; CURI, N.; MARQUES, J.J.G.S.M.; GUILHERME, L.R.G.; LIMA, J.M. Ponto de efeito salino nulo e suas relações com propriedades mineralógicas e químicas de Latossolos brasileiros. Pesquisa Agropecuária Brasileira, v.31, p.663671, 1996.

SINGH, B.; GILKES, R.J. Properties of soil kaolinites from South Western Australia. Journal Soil Science, v.43, p.645-667, 1992.

SINGH, U.; UEHARA, G. Electrochemistry of the double layer: principles and applications to soils. In: SPARKS, D.L. (Ed.) Soil physical chemistry. Boca Raton: CRC, 1986. p.2-38.

SINGH, U.; UEHARA, G. Electrochemistry of the double layer: principles and applications to soils. In: SPARKS, D.L. (Ed.) Soil physical chemistry. 2.ed. Boca Raton: CRC, 1998. p.1-46.

SIQUEIRA, C.; LEAL, J.R.; VELLOSO, A.C.X. Eletroquímica de solos tropicais de carga variável: II. Quantificação do efeito da matéria orgânica sobre o ponto de carga zero. Revista Brasileira de Ciência do Solo, v.14, p.13-17, 1990.

SPARKS, D.L. Environmental soil chemistry. San Diego: Academic Press, 1995. 267p.

SPOSITO, G. The operational definition of the Zero Point of Charge in soils. Soil Science Society of America Journal, v.45, p.292- 297, 1981.

SPOSITO, G. On the measurement of permanent charge in Oxisols. Soil Science Society of America Journal, v.47, p.1058-1059, 1983.

SPOSITO, G. Surface reactions in natural aqueous colloidal systems. Chimia, v.43, p.169-176, 1989a.

SPOSITO, G. The chemistry of soils. New York: Oxford University Press, 1989b. 277p.

SPOSITO, G. The characterization of particles surface charge. In: BUFFLE, J.; van LEEUVEN, H.P. (Ed.) Environmental particles. Lewis Publishers, v.1. 1992. p.291-314. (Publications in Environmental and Analytical Chemistry)

SPOSITO, G. The surface chemistry of soils. New York: Oxford University Press, 1984. 234p.

STOOP, W.A. Ion adsorption mechanisms in oxidic soils; implications for point of zero charge determinations. Geoderma, v.23, p.303-314, 1980.

STUMM, W. Chemistry of the solid-water interface. New York: John Wiley \& Sons, 1992. 428p.

SVERJENSKY, D.A. Physical surface-complexation models for sorption at the mineral-water interface. Nature, v.364, p.776-780, 1993.

SVERJENSKY, D.A. Zero-point-of-charge prediction from crystal chemistry and solvation theory. Geochimica et Cosmochimica Acta, v.58, p.3123-3129, 1994.

TESSENS, E.; SHAMSHUDDIN, J. Characteristics related to charges in Oxisols of Peninsular Malaysia. Pedologie, v.32, p.85-106, 1982.

TESSENS, E.; ZAUYAH, S. Positive permanent charge in Oxisols. Soil Science Society of America Journal, v.46, p.1103-1106, 1982.

TONER IV, C.V.; SPARKS, D.L.; CARSKI, T.H. Anion exchange chemistry of Middle Atlantic soils: charge properties and nitrate retention kinetics. Soil Science Society of America Journal, v.53, p.1061-1967, 1989.

TORRENT, J.; BARRÓN, V. Laboratory measurement of soil colour. In: BIGHAM, J.M.; CIOLKOSZ, E.J. (Ed.) Soil colour. Madison: Soil Science Society of America, 1993. p.21-33. (Special Publication) 
TORRENT, S.; BARRÓN, V.; SCHWERTMANN, U. Phosphate adsorption and desorption by goethites differing in crystal morphology. Soil Science Society of America Journal, v.54, p.1007-1912, 1990.

UEHARA, G.; GILLMAN, G.P. Charge characteristics of soils with variable and permanent charge minerals: I. Theory. Soil Science Society of America Journal, v.44, p.250-252, 1980.

UEHARA, G.; GILLMAN, G.P. The mineralogy, chemistry and physics of tropical soils with variable charge clays. Boulder: Westview Press, 1981. 170p.

WADA, K.; OKAMURA, Y. Net charge characteristics of Dystrandept $B$ and theoretical prediction. Soil Science Society of America Journal, v.47, p.902-905, 1983.

WADA, S.J.; WADA, K. Charge characteristics and exchangeable cation status of Korean Ultisols and Alfisols and Thai Ultisols and Oxisols. Journal of Soil Science, v.36, p.21-29, 1985.

WANN, S.S.; UEHARA, G. Surface charge manipulation of constant surface potential soil colloids: I. Relation to sorbed phosphorus. Soil Science Society of America Journal, v.42, p.565-570, 1978.
WHITE, G.N.; ZELAZNY, L.W. Charge properties of soil colloids. In: SPARKS, D.L. (Ed.) Soil physical chemistry. Boca Raton: CRC Press, 1986. p.39-81.

YOON, R.H.; SALMAN, T.; DONNAY, G. Predicting points of zero charge of oxides and hydroxides. Journal of colloid and interface science, v.70, p.483-493, 1979.

ZHANG, X.N.; ZHAO, A.Z. Surface charge. In: YU, T.R. (Ed.) Chemistry of variable change soils. New York: Oxford University Press, 1997. p.17-63.

ZHANG, X.N.; ZHANG, G.Y.; ZHAO, A.Z.; YU, T.R. Surface electrochemical properties of the $B$ horizon of a Rhodic Ferralsol, China. Geoderma, v.44, p.275-286, 1989.

$\overline{\text { Recebido em } 28.06 .00}$ 